https://russjcardiol.elpub.ru

ISSN 1560-4071 (print)

ISSN 2618-7620 (online)

\title{
The year in cardiovascular medicine 2020: interventional cardiology
}

Fernando Alfonso $^{1 \star}$, Nieves Gonzalo ${ }^{2}$, Fernando Rivero ${ }^{1}$, Javier Escaned ${ }^{2}$

${ }^{1}$ Cardiology Department, Hospital Universitario de la Princesa, Instituto de Investigación Sanitaria IIS-IP, Universidad Autónoma de Madrid, CIBERCV, C/Diego de León 62 , Madrid 28006, Spain; ${ }^{2}$ Cardiology Department, Hospital Clinico San Carlos, IdISSC, Universidad Complutense de Madrid. C/ Martín Lagos s/n 28042 Madrid, Spain.

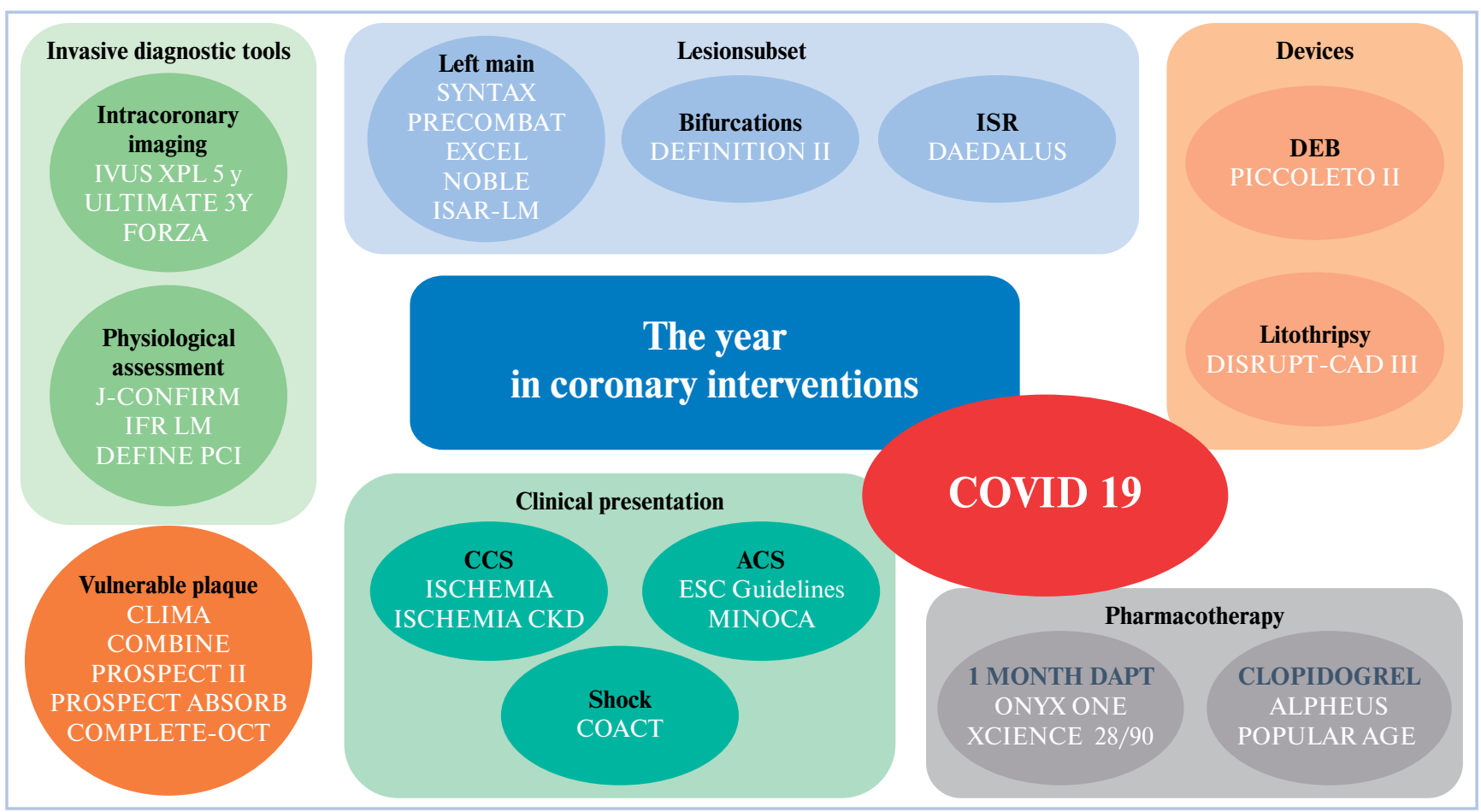

The year in coronary interventions. ACS - acute coronary syndrome, CCS - chronic coronary syndrome, COVID-19 - coronavirus disease-19, DEB - drug-eluting balIoon, DAPT — dual antiplatelet therapy, ISR - in-stent restenosis.

Keywords: acute coronary syndromes, chronic coronary syndromes, myocardial infarction, coronavirus disease 19, clinical practice guidelines, drug-eluting stents, drugcoated balloons, antiplatelet drugs, coronary revascularization, stent thrombosis, left main coronary artery, in-stent restenosis, intravascular ultrasound, optical coherence tomography, cardiogenic shock, vulnerable plaque, coronary physiology, myocardial ischaemia.

The opinions expressed in this article are not necessarily those of the Editors of the European Heart Journal or of the European Society of Cardiology.

*Corresponding author. Tel: +34 680483165, Email: falf@hotmail.com

Published on behalf of the European Society of Cardiology. All rights reserved. VC The Author(s) 2021. For permissions, please email: journals.permissions@oup.com.

Received 11 November 2020; revised 11 December 2020; editorial decision 23 December 2020; accepted 23 December 2020

(c) BY 4.0

Статья опубликована: European Heart Journal (2021) 00, 1-19. doi:10.1093/eurheartj/ehaa1096 


\section{Год в сердечно-сосудистой медицине 2020: интервенционная кардиология}

Fernando Alfonso ${ }^{1 *}$, Nieves Gonzalo ${ }^{2}$, Fernando Rivero ${ }^{1}$, Javier Escaned ${ }^{2}$

${ }^{1}$ Cardiology Department, Hospital Universitario de la Princesa, Instituto de Investigación Sanitaria IIS-IP, Universidad Autónoma de Madrid, Maдрид; ${ }^{2}$ Cardiology Department, Hospital Clinico San Carlos, IdISSC, Universidad Complutense de Madrid, Мадрид, Испания.

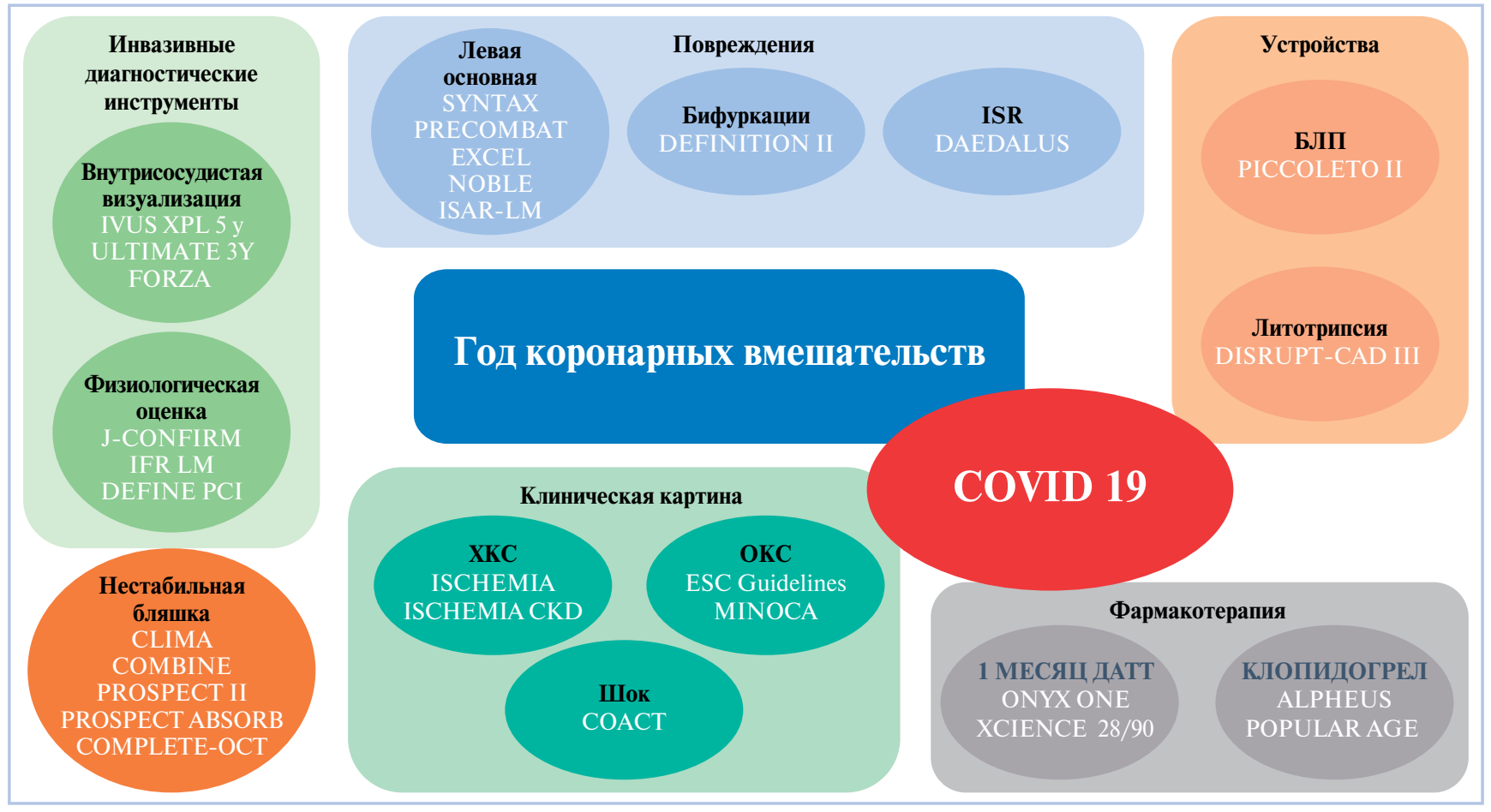

Год коронарных вмешательств. ОКС - острый коронарный синдром, ХKC - хронический коронарный синдром, COVID-19 - коронавирусная инфекция-19, БлП - баллон с лекарственным покрытием, ДАТT - двойная антитромбоцитарная терапия, ISR - рестеноз стента.

Ключевые слова: острый коронарный синдром, хронический коронарный синдром, инфаркт миокарда, коронавирусная инфекция 19, руководства по клинической практике, стенты с лекарственным покрытием, баллоны с лекарственным покрытием, антитромбоцитарные препараты, коронарная реваскуляризация, тромбоз стента, ствол левой коронарной артерии, рестеноз стента, внутрисосудистое ультразвуковое исследование, оптическая когерентная томография, кардиогенный шок, нестабильные бляшки, коронарная физиология, ишемия миокарда.

\section{Introduction}

Percutaneous coronary interventions (PCI) constitute the most widely used revascularization modality in patients with coronary artery disease (CAD). The past year witnessed major advances in the treatment of patients with acute coronary syndromes (ACS) and acute myocardial infarction (MI), including both STsegment elevation (STEMI) and non-ST-segment elevation (NSTEMI), together with the presentation of a new clinical practice guideline (CPG). Management of patients with chronic coronary syndrome with demonstrable ischaemia has been specifically addressed by a new pivotal randomized trial. Significant advancements in the treatment specific lesion subsets together with novel data on long-term results of interventional devices have been published. Moreover, the value of physiological assessment before and after PCI has been consolidated, whereas new coronary imaging trials shed new light on the never-ending quest of the vulnerable plaque. Finally, advances in antithrombotic management, particularly addressing very short duration regimens, have been presented.

However, without any doubt, 2020 will be remembered as the year of the pandemic. Indeed, coronavirus disease-19 (COVID-19) drastically disrupted health care around the world, posing unprecedented challenges in the care of patients with cardiovascular diseases and CAD in particular (Graphical abstract).

\section{COVID-19}

Myocardial damage related to COVID-19 has been a subject of major clinical interest due to its prognostic implications. Non-ischaemic myocardial injury and myocarditis have been demonstrated in severe cases with this condition [1-5]. In addition, the intense inflammatory and prothrombotic milieu found in patients 
A

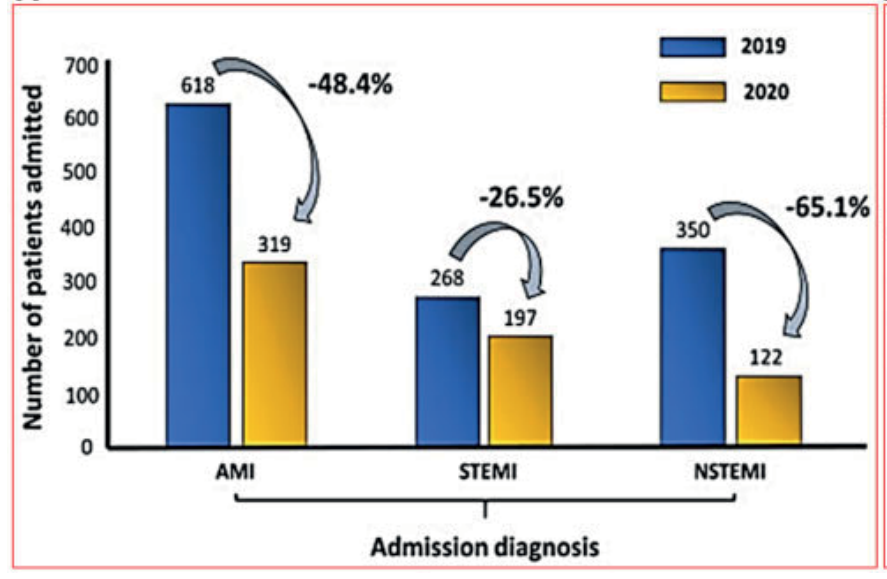

B

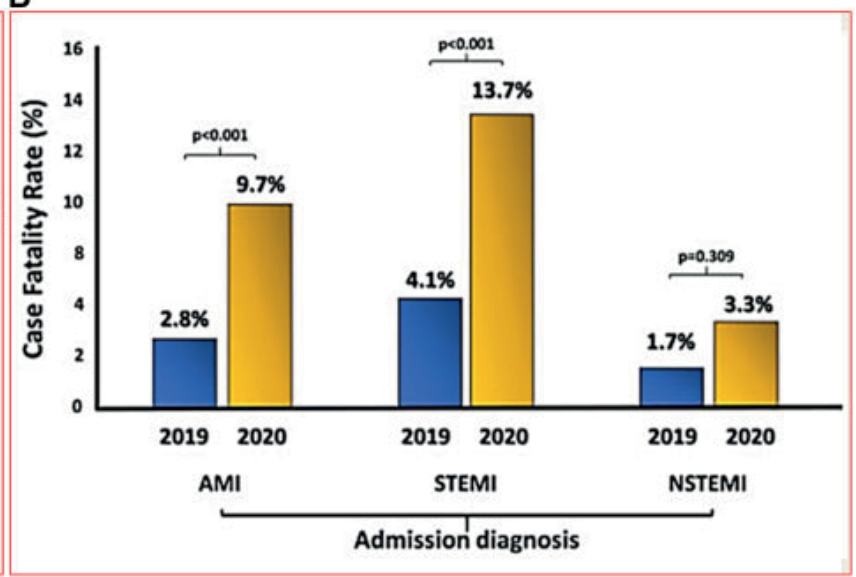

Figure 1. (A) Admissions for acute myocardial infarction across Italy. Number of admissions registered among Italian cardiac care units (CCUs) during the week $12-19$ March 2020, in the midst of the COVID-19 emergency (yellow bars) and during the same week of the previous year (blue bars) for comparison. (B) Case fatality rates for acute myocardial infarction. Image obtained with permission from De Rosa et al. [18].

with severe COVID-19 disease has been considered a potential trigger of MI as a result of plaque rupture. Likewise, cases associated with severe coronary spasm, Takotsubo syndrome, spontaneous coronary artery dissection, and stent thrombosis have been reported [6-8]. A series from New York of COVID-19 patients with STEMI demonstrated a heterogeneous clinical presentation with a high prevalence (one-third of patients) of non-obstructive CAD and a poor prognosis $(72 \%$ hospital mortality). In some patients, myocardial injury, rather than MI, was considered secondary to the cytokine storm, hypoxic injury, coronary spasm, microthrombi or, endothelial damage [9]. Furthermore, several studies demonstrated a prominent role of systemic thrombotic complications (both arterial and venous) in COVID-19 patients with some observational data suggesting a benefit of anticoagulation therapy in selected patients [10]. Notably, STEMI patients with concurrent COVID-19 infection appear to have larger thrombus burden and poorer outcomes. An observational study compared the characteristics and results of STEMI patients with and without concurrent COVID-19 infection. STEMI patients with COVID-19 had higher levels of troponin T, D-dimer, C-reactive protein, and lower lymphocyte counts. These patients had higher thrombus grade, more frequent multivessel thrombosis and stent thrombosis, needed more often the use of glycoprotein IIb/IIIa inhibitors and thrombus aspiration, but, eventually, had a poorer left ventricular ejection fraction (LVEF) [11].

COVID-19 had also a striking and unexpected effect on PCI activity around the world. A question was ubiquitously asked at the beginning of the pandemic: where have all the patients with acute MI gone? A significantly delayed hospital presentation after symptoms onset was consistently noticed [12, 13]. Some have suggested increasing use of fibrinolytic therapy rather than primary PCI for patients with STEMI, given delays to catheterization laboratory arrival, and to avoid exposing staff to COVID. However, studies have confirmed that in spite of the logistic challenges, primary PCI remains the therapy of choice for STEMI during the pandemic [1416]. Subsequently, cardiovascular mortality was found to play a major role in the 'excess in mortality' seen during the pandemic. A significant decrease in ACS-related hospitalization in northern Italy during the early days of the COVID-19 outbreak suggested that the total increase in mortality (not fully explained by COVID-19 cases alone) would be the result of ACS patients dying without seeking medical attention [15-18] (Figure 1). A study from England confirmed the reduced number of admissions and PCI for ACS during the pandemic, particularly among NSTEMI patients [19]. The risk for an increase in out-of-hospital death and long-term complications of MI was a cause of major concern. Another study from the Lombardia region demonstrated a strong correlation between the cumulative incidence of out of hospital cardiac arrest and the COVID-19 cumulative incidence per 100000 inhabitants [15]. Accordingly, modified diagnostic and treatment algorithms were rapidly developed to adapt classical protocols to this unprecedented sanitary challenge. The need for drastic reorganization of catheterization laboratories, including protection measures for healthcare providers, ACS networks (with redistribution of hub and spoke hospitals), and reshaping of emergency rooms and cardiac units, soon became apparent worldwide [20].

\section{Chronic coronary syndromes}

The long-awaited results of the International Study of Comparative Health Effectiveness with Medical and Invasive Approaches (ISCHEMIA) trial were published in 2020 [21]. The trial investigated in a 1:1 randomized 
A

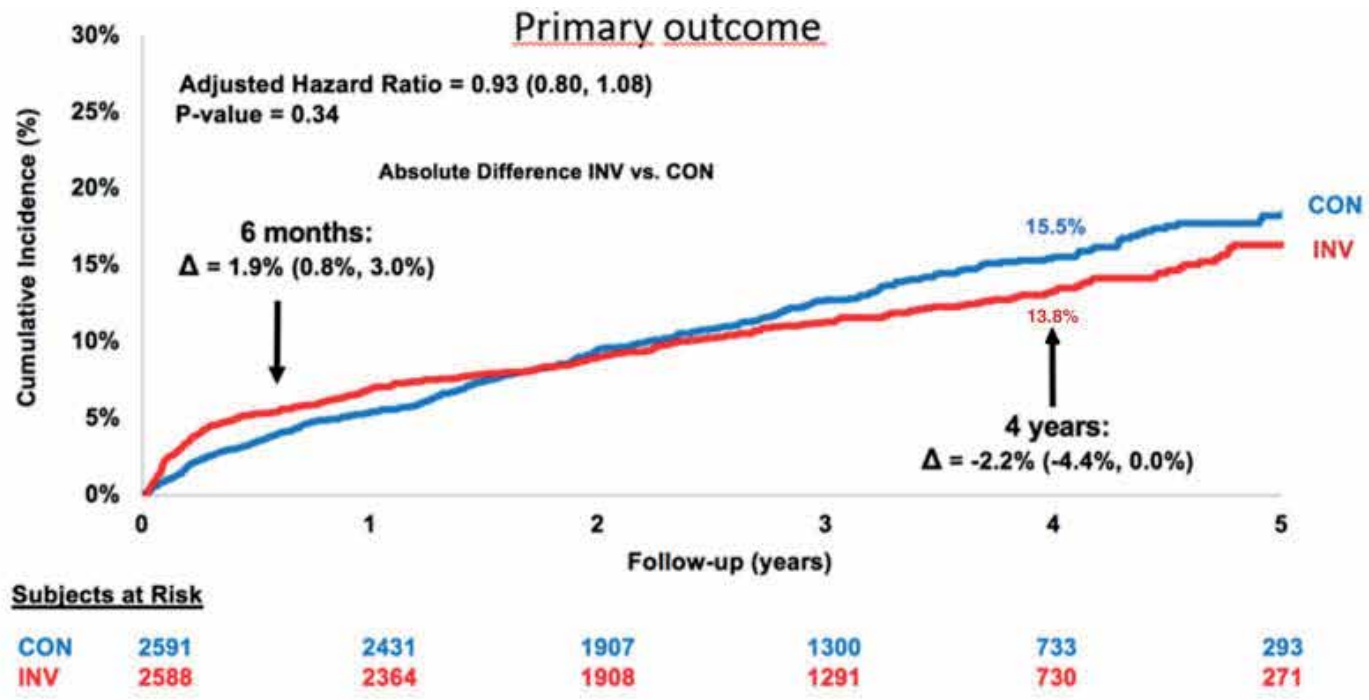

B

\section{Procedural MI (Types 4a or 5)}

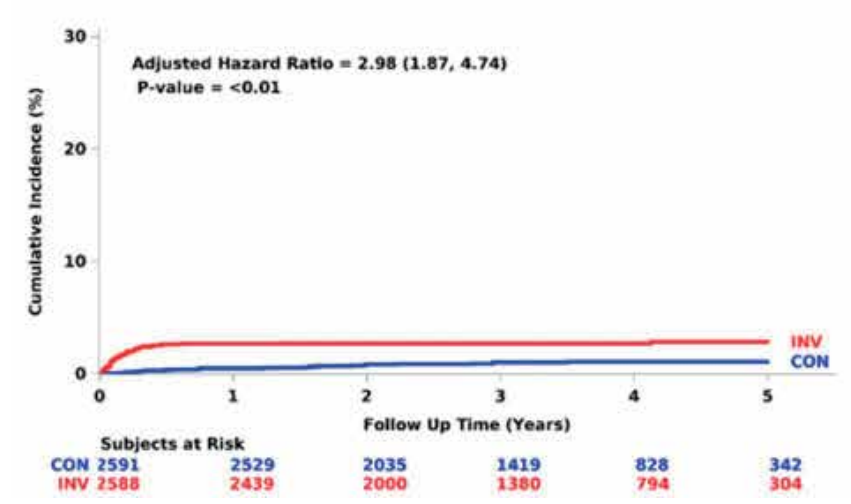

c

Spontaneous MI (Types 1, 2,4b or 4c)

Figure 2. The ISCHEMIA trial. (A) The primary endpoint (cumulative incidence of death from cardiovascular causes, myocardial infarction, or hospitalization for unstable angina, heart failure, or resuscitated cardiac arrest) in the conservative-strategy group and the invasive strategy group is shown. (B and $\mathbf{C}$ ) The cumulative incidence of MI. Image obtained with permission from Spertus et al. [22].

fashion if, in patients with stable CAD and moderate or severe ischaemia, an initial invasive strategy of cardiac catheterization and optimal revascularization, in addition to optimal medical treatment (OMT), would improve clinical outcomes compared with an initial conservative strategy of OMT alone with coronary angiography reserved for failure of medical therapy. In total, 5179 patients were enrolled in the trial. Importantly, cardiac computed tomography was required before randomization in patients without severe kidney disease to exclude the presence of left main coronary artery disease (LMCAD) or non-obstructive CAD. At 5-year follow-up, no superiority of the invasive over the medical strategy was documented. The estimated cumulative event rate of the primary endpoint (a composite of death from cardiovascular causes, MI, or hospitalization for unstable angina, heart failure, or resuscitated cardiac arrest) was $16.4 \%$ in the invasive-strategy group and
$18.2 \%$ in the conservative-strategy group [difference, -1.8 percentage points; $95 \%$ confidence interval (CI) -4.7 to 1.0 ] (Figure $2 \mathrm{~A}$ ). In terms of mortality, there was no significant difference in all-cause mortality in the two study groups. Of note, while associated with more procedural $\mathrm{MI}$, in the long term, the invasive strategy demonstrated to be superior to the conservative one in terms of spontaneous MI (Figure 2 B and C). Furthermore, the invasive strategy leads to greater improvement in angina-related health status than the conservative strategy, with a sustained improvement in quality of life that was maintained through 3 years [22]. Due to the study exclusion criteria, the findings of the ISCHEMIA trial do not apply to patients with ACS, LMCAD, reduced LVEF, heart failure (class III or IV), or severe angina despite maximal medical therapy. Among a more complex population of patients with chronic kidney disease, the ISCHEMIA-CKD 
A

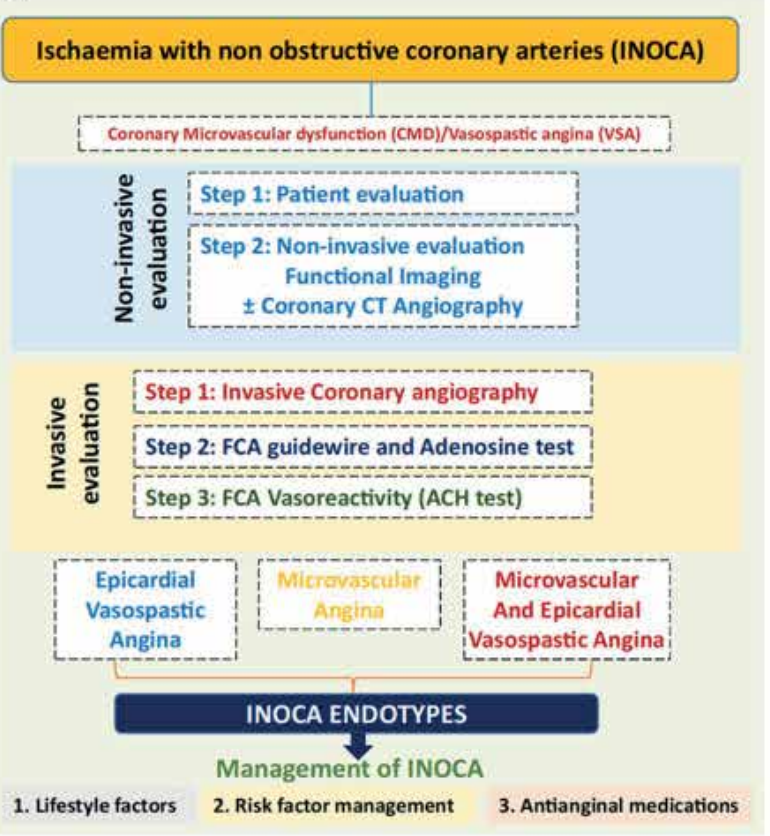

B

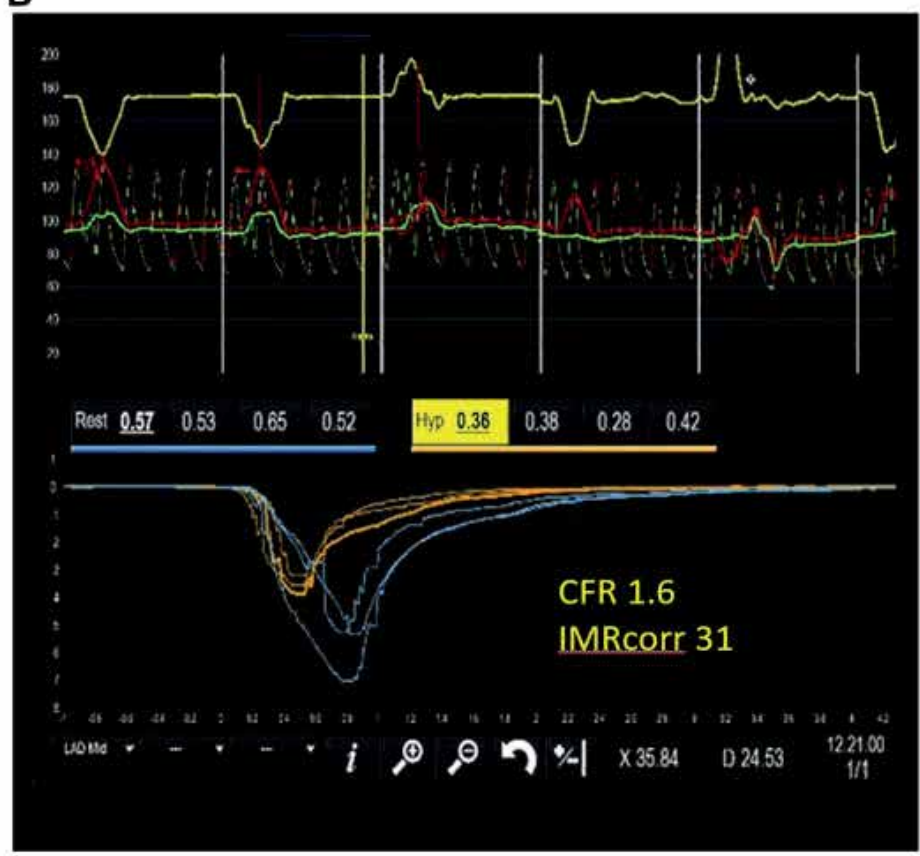

Figure 3. (A) Management of patients with ischaemia and normal coronary arteries (INOCA). (B) Case example of a patient with angiographically normal coronary arteries in whom microvascular dysfunction was invasively studied using coronary flow reserve (CFR) and the index of myocardial resistance (IMR). (A) Image obtained with permission from Kunadian et al. [27].

randomized trial failed to detect any benefit (primary endpoint mortality and MI) in the invasive compared with the conservative strategy [23].

A study-level meta-analysis of 14 randomized clinical trials (RCT) (14877 patients) comparing routine revascularization vs. an initial conservative strategy in patients with stable ischaemic heart disease including also the two ISCHEMIA trials reported that, despite similar rates of all-cause death, cardiovascular death, MI, heart failure, or stroke in the invasive and conservative approaches, an invasive strategy is associated with reduced risks of non-procedural MI, unstable angina, and superior rates of freedom from angina, at the cost of an increased risk of procedural MI [24].

The 2019 European Society of Cardiology (ESC) CPG on the Diagnosis and Management of Chronic Coronary Syndromes introduced several new recommendations of particular interest for interventional cardiologists [25]. Invasive angiography was recommended as an alternative test to diagnose CAD in patients with a high clinical likelihood and severe symptoms refractory to medical therapy, or typical angina at a low level of exercise and clinical evaluation that indicates high event risk (IA class and level of recommendation). The recommendation specifies that invasive functional assessment must be available and used to evaluate stenosis before revascularization, unless very high grade $(>90 \%$ diameter stenosis), providing an important support to the use of physiology in the catheterization laboratory. The coronary sinus reducer device received an IIb recommendation to ameliorate symptoms of debilitating angina refractory to OMT and revascularization strategies [26]. Of note, the diagnosis of microvascular angina in the catheterization laboratory is strongly supported by these CPG. New recommendations include the use of intracoronary measurements of coronary flow reserve and microvascular resistance (IIa B), as well as the use of acetylcholine testing (IIb B), in patients with persistent symptoms but coronary arteries that are either angiographically normal or have moderate stenoses with preserved instantaneous wave-free ratio (iwFR) or fractional flow reserve (FFR). Ample information on how to outline vascular dysfunction pathways in patients with ischaemia with nonobstructive coronary arteries, and on how to set stratified treatment on the grounds of the obtained information, has been put together into a dedicated, expert document published by the European Association of Percutaneous Coronary Interventions (EAPCI) in conjunction with scientific working groups (Figure 3) [27]. Finally, a recent study on women $(n=301)$ presenting with MI and angiographically non-obstructed coronary arteries demonstrated the value of optical coherence tomography (OCT) and cardiac magnetic resonance imaging (CMR) to identify a potential mechanism for the acute event in $84.5 \%$ of patients $(63.8 \%$ had a ischaemicand $20.7 \%$ a nonischaemic aetiology) [28].

\section{Acute coronary syndromes}

Non-ST-segment elevation myocardial infarction. This year, a new ESC CPG on the management of ACS 


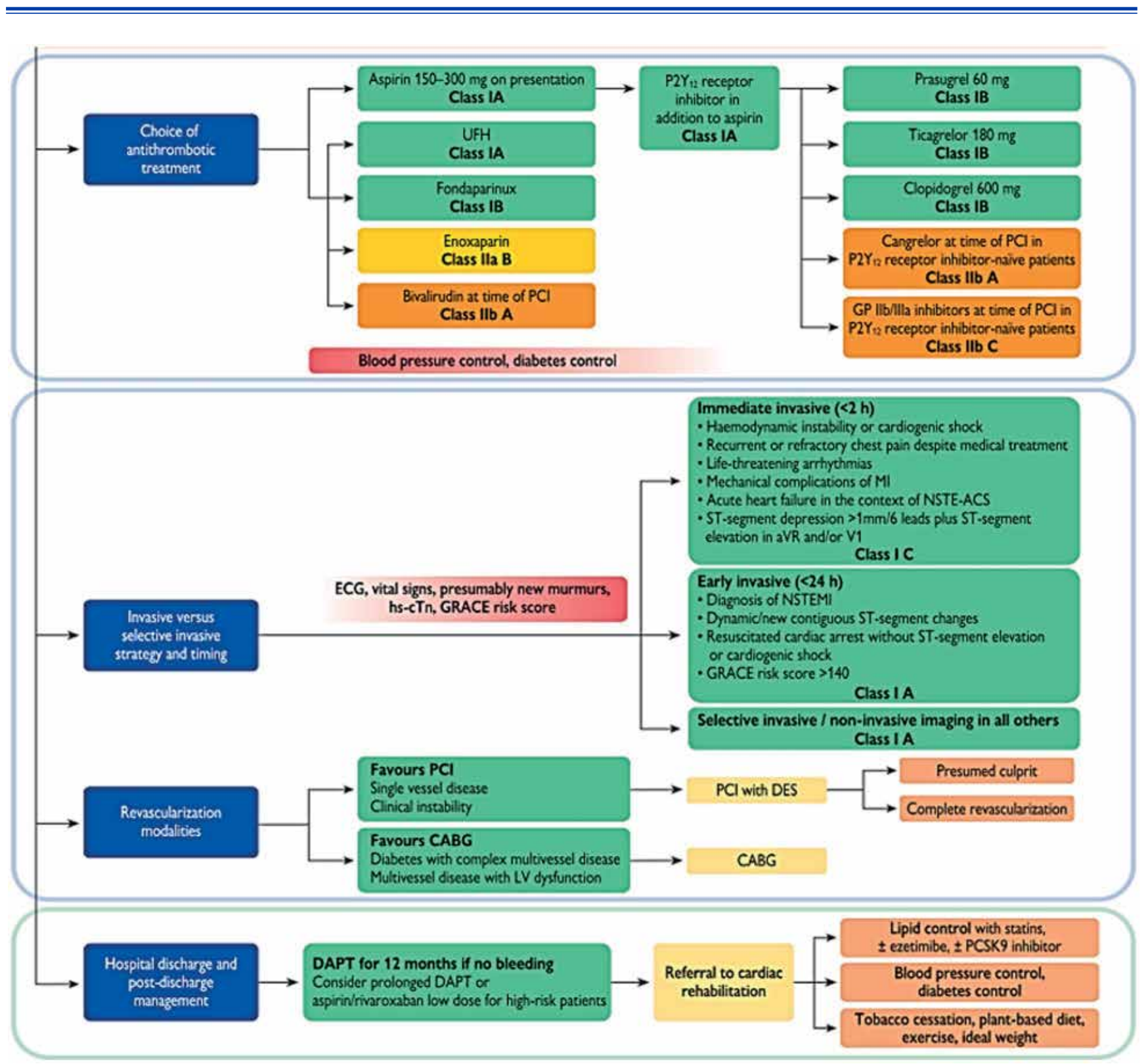

Figure 4. Management strategy for non-ST-segment elevation acute coronary syndrome patients according to the new ESC CPG. CABG, coronary artery bypass graft(ing); DAPT, dual antiplatelet therapy; DES, drug-eluting stent; ECG, electrocardiogram/electrocardiography; GP, glycoprotein; GRACE, Global Registry of Acute Coronary Events; hs-cTn, high-sensitivity cardiac troponin; NSTEACS, non-ST-segment elevation acute coronary syndrome; NSTEMI, non-ST-segment elevation myocardial infarction; PCl, percutaneous coronary intervention; PCSK9, protein convertase subtilisin kexin 9; UFH, unfractionated heparin. Image obtained with permission from Collet et al. [29].

patients without persistent STEMI was issued [29]. This guideline facilitates decision making in daily practice and includes a set of quality indicators to assess the level of implementation and clinical outcomes. New recommendations for these patients regarding diagnosis and medical treatment included the ESC high-sensitive cardiac troponin $\mathrm{T}$ (hscTnT) blood sampling $0 \mathrm{~h} / 2 \mathrm{~h}$ algorithm as an alternative to the $0 \mathrm{~h} / 1 \mathrm{~h}$ algorithm (I), no need for other biomarkers in addition to hscTnT for diagnostic purposes (III), use of B-type natriuretic peptide (BNP)/N-terminal pro-B-type natriuretic peptide for risk stratification (IIa), prasugrel preferred to ticagrelor for patients proceeding to PCI (IIa), P2 $\mathrm{Y}_{12}$ pretreatment for patients who cannot undergo early invasive management (IIb) but not for patients with unknown anatomy planned for early invasive management (III), de-escalation of $\mathrm{P} 2 \mathrm{Y}_{12}$ for patients unsuitable for potent platelet inhibition (IIb), use of novel oral anticoagulants and a single antiplatelet agent after 1week of triple therapy in patients with atrial fibrillation with embolic risk (I), and discontinuation of antiplatelet therapy at 1 year in patients requiring oral anticoagulation (I) [29]. Alternatively, new recommendations regarding invasive treatment included an early invasive strategy $(<24 \mathrm{~h})$ for 
high-risk patients (I), selective invasive strategy for low risk patients following non-invasive imaging/ischaemia detection tests (I), delayed (rather than immediate) coronary angiography for cardiac arrest survivors without STEMI (IIa), complete revascularization for patients without cardiogenic shock (IIa) (IIb to be accomplished during index procedure), FFR-guided complete revascularization during index procedure (IIb) [29]. A summary of management recommendations is presented in Figure 4.

ST-segment elevation myocardial infarction (STEMI). The very long-term safety and efficacy of drugeluting stents (DES) in STEMI patients were recently confirmed. The 10-year results of the EXAMINATION trial demonstrated the superiority of everolimus-DES compared with bare-metal stents (BMS) regarding the primary efficacy endpoint [30]. Interestingly, the landmark analysis beyond 5 years showed identical and very low event rates with the two strategies [30]. In asymptomatic patients with 'transient' STEMI, an immediate invasive strategy was unable to reduce CMR-assessed infarct size compared to an early invasive strategy [31]. A large cohort study using routine clinical data from tertiary UK centres suggested that less than half of octogenarians with STEMI/NSTEMI underwent invasive management. Interestingly, the adjusted cumulative 5 -year mortality rate was $36 \%$ in the invasive management group and 55\% in the noninvasive management group [32]. Several new metaanalyses, including data from the COMPLETE trial, comparing complete vs. culprit-only revascularization in STEMI patients supported the value of complete revascularization to reduce rates of re-infarction, cardiovascular mortality, and repeat revascularization with no difference in all-cause mortality [33]. Likewise, in patients with NSTEMI, an observational study suggested that multivessel revascularization reduced 3-year rates of major adverse cardiac events (MACE) (total death, MI, any revascularization) compared with culprit-vesselonly revascularization [34]. However, in this study, 1-stage multivessel revascularization was not superior to multistage revascularization except in low-to intermediate risk patients [34].

Cardiac arrest/shock. The Coronary Angiography after Cardiac Arrest (COACT) randomized trial enrolled 552 patients successfully resuscitated after outof hospital cardiac arrest without electrocardiographic signs of STEMI [35]. The 1-year survival $(61.4 \%$ vs. $64.0 \%$ ) and MACE rates were similar in the immediate vs. delayed angiography strategies [35]. In a populationbased registry from Paris, $4 \%$ of out-of-hospital cardiac arrests were treated with extracorporeal-cardiopulmonary resuscitation (CPR), which was not associated with increased hospital survival [36]. However, in the extracorporeal-CPR group, initial shockable rhythm and pre-hospital extra-corporeal membrane oxygenation
(ECMO) implantation improved clinical outcomes. The value of routine mechanical circulatory support in patients with cardiogenic shock remains controversial even though these devices are increasingly used as the ultimate option for these critically ill patients. A metaanalysis of randomized trials suggested no reduction in mortality with the use of Impella or intra-aortic balloon in patients undergoing high-risk PCI or cardiogenic shock, but a significant increase in vascular complications [37]. However, another concurrent meta-analysis of observational studies suggested the potential value of the new generations of the Impella device in selected patients in cardiogenic shock [38]. Finally, data from a large nationwide administrative database in patients with acute MI and cardiogenic shock suggested that the adjusted mortality rate was lower in patients no-electively treated with Impella than in those receiving venoarterial (VA)ECMO [39]. Finally, in a large (686 patients) multicentre cohort study, left ventricular unloading with Impella reduced mortality in patients in cardiogenic shock treated with VAECMO despite higher complication rates (mainly access site-related and renal replacement therapy) [40]. Many studies on this field are currently limited by a retrospective design, observational nature, and reduced sample size. Accordingly, controlled studies are required to further elucidate the value of mechanical circulatory support in patients undergoing high-risk interventions and in those with cardiogenic shock.

\section{Lesion subsets}

Left main and multivessel disease. The last year provided significant information on long-term outcomes of patients with LMCAD treated with PCI vs. coronary artery bypass grafting (CABG). One of the sources for such evidence is the SYNTAX trial, which randomized patients with LMCAD or 3-vessel disease to PCI with first-generation paclitaxel-eluting stent $(n=903)$ vs. CABG $(n=897)$ [41]. Information on vital status at 10 years was obtained for $841(93 \%)$ patients in the PCI group and 848 (95\%) patients in the CABG group showing no significant differences in all cause death between the two treatment modalities. At 10 years, 248 (28\%) patients had died in the PCI and $212(24 \%)$ in the CABG study groups [hazard ratio (HR) 1.19 (95\% CI 0.99-1.43), $\mathrm{P}=0.066]$. When analysed separately, allcause mortality was higher in the PCI group in patients with 3-vessel disease, but not in patients with LMCAD [41]. These data should be interpreted taking into consideration that PCI in this trial was performed using a first-generation DES (Taxus ${ }^{\mathrm{TM}}$ ) with rates of late stent thrombosis superior to current generation DES and not currently available for clinical practice.

The PRECOMBAT trial (Premier of Randomized Comparison of Bypass Surgery vs. Angioplasty Using Sirolimus-Eluting Stent in Patients with Left Main Coronary Artery Disease), randomized 600 patients 
with LMCAD to PCI with sirolimus-eluting stents or CABG. The extended 10-year follow-up published this year showed no differences between the two groups in the primary outcome (composite of all-cause death, MI, stroke, or ischaemia-driven target-vessel revascularization). Ischaemia-driven target-vessel revascularization (TVR) was more frequent after PCI than after CABG [16.1\% vs. 8.0\%; HR 1.98 (95\% CI 1.21-3.21)] [42]. Two RCT comparing PCI vs. CABG for LMCAD treatment have reported their 5 year follow-up results. The EXCEL study that randomized 1905 patients with LMCAD to be treated with PCI (with everolimusDES) or CABG showed no differences between groups for the combined endpoint of all-cause death, MI, or stroke (22.0\% for PCI and $19.2 \%$ for CABG) [43]. Patients treated with PCI showed an increased allcause mortality $(13.0 \%$ vs. $9.9 \%)$ and higher rates of revascularization $(16.9 \%$ vs. $10.0 \%)$ while cerebrovascular events were more frequent in patients treated with CABG (3.3\% vs. 5.2\%). There were no differences between PCI and CABG in cardiovascular death $(5.0 \%$ vs. $4.5 \%)$ or MI ( $10.6 \%$ and $9.1 \%$, respectively). The 5 -year follow-up of the NOBLE study that randomized 1201 patients with LMCAD to PCI with DES (88\% biolimus-DES) or CABG showed a higher incidence of MACE (composite of all-cause mortality, nonprocedural MI, repeat revascularisation, and stroke) in patients treated with PCI (28\% for PCI and 19\% for $\mathrm{CABG}$ ). Interestingly, there were no differences in allcause mortality ( $9 \%$ for both groups), but patients treated with PCI had higher rates of non-procedural MI (8\% vs. $3 \%$ ) and repeat revascularisation (17\% vs. 10\%) [44]. Table 1 presents the results of the RCT comparing PCI vs. CABG for the treatment of LMCAD with long-term clinical follow-up. To summarize the long-term results of LMCAD revascularization, a meta-analysis of the four RCT comparing PCI and CABG for the treatment of LMCAD with $>5$ years follow-up reported no differences in all-cause death and cardiovascular death between the two types of revascularization. MACE was higher in the PCI group mainly in relation with an increase in MI and revascularizations [45]. A second meta-analysis including 4595 patients with LMCAD from five RCT showed no differences in all-cause mortality or MI between CABG and PCI with higher rates of revascularization in the PCI group at 5 years' follow-up [46]. Finally, the most recent meta-analysis comparing the two types of revascularization included 4612 patients from five trials [47]. No differences were found between PCI and CABG regarding all-cause mortality or cardiac death. No significant differences were observed between therapies in the risk of stroke or MI but PCI was associated with an increased risk of revascularization.

Several sub-studies of the EXCEL trial have been reported in the past year. One of them evaluated the impact of periprocedural MI on mortality. Periprocedural
MI [defined as creatinine kinase-MB (CKMB) elevation $>10 \times$ the upper reference limit (URL) within $72 \mathrm{~h}$ postprocedure, or $>5 \times$ URL with new Q-waves, angiographic vessel occlusion, or loss of myocardium on imaging] was more frequent after CABG and was associated with 3-year all-cause death and cardiovascular death for both modalities of revascularization. Only increases of biomarkers indicating large necrosis (CK-MB $>10 \times$ URL) were related to mortality [48]. A second subanalysis of the EXCEL trial explored the influence of repeat revascularizations on mortality. PCI was associated with higher rates of any repeat revascularization, and the need for repeat revascularization by CABG (but not by PCI) was independently associated with increased risk for 3-year all-cause and cardiovascular mortality after both CABG and PCI [49]. Another sub-analysis of the EXCEL trial showed that a reduced LVEF $(<40 \%)$ was associated with an increased 3-year rate of the composite of death, stroke, and MI driven mainly by an increased rate of all-cause death [50]. However, this study did not show any significant differences between PCI and CABG irrespective of the underlying LVEF [50].

A patient-level pooled analysis of the randomized ISAR-LEFTMAIN and ISAR-LEFT-MAIN-2 trials, in which patients underwent treatment of LMCAD with DES, was reported. The 5-year mortality rate was higher in patients with target lesion revascularization (TLR) compared with those without. In this analysis, severe renal dysfunction, COPD, and body mass index were independent predictors of mortality while type of stent and type of repeat revascularization did not influence mortality [51]. Other studies published this year evaluated the influence of the LVEF on LMCAD revascularisation. A study performed in South Korea evaluated a total of 3488 patients with LMCAD who underwent CABG $(n=1355)$ or PCI $(n=2133)$ from the IRIS-MAIN (Interventional Research Incorporation Society-Left MAIN Revascularization) registry [52]. The authors found no differences in the composite of death, MI, or stroke between the two treatment strategies when the patients had normal or mildly reduced LVEF. However, as compared with CABG, PCI was associated with a higher adjusted risk of the primary outcome in patients with reduced LVEF [52].

Regarding strategies of revascularization in patients with multivessel disease, a registry from Canada analysing with propensity match diabetic patients with 2- or 3-vessel disease who underwent PCI or CABG showed a higher mortality and MACE rates in patients treated percutaneously at a median follow-up of 5.5 years [53]. These results should, however, be interpreted with caution as this study suffers from limitations (e.g. significant differences in the rates of complete revascularization between the two groups even after propensity score matching).

Bifurcations. The DEFINITION II trial randomized 653 patients with complex bifurcation lesions according 


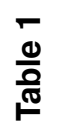

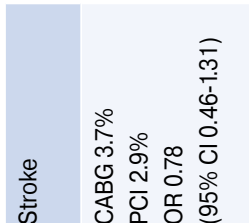

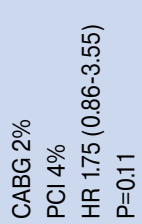

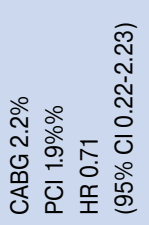

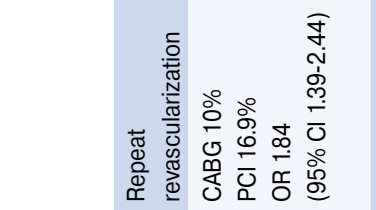

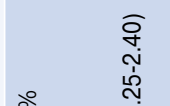

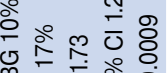

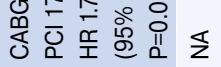

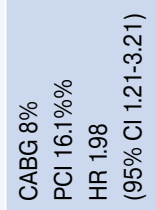

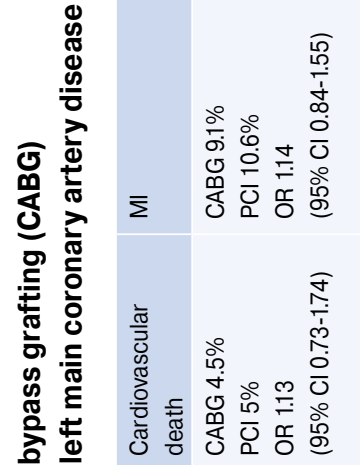

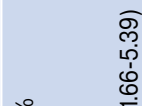

今े

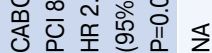

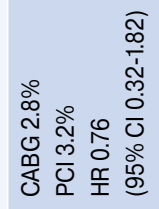

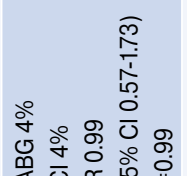

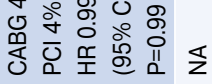

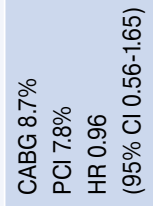

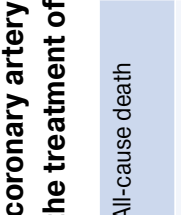

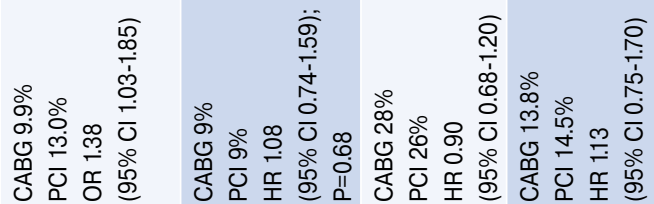

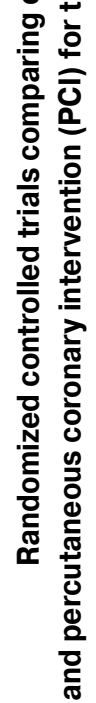

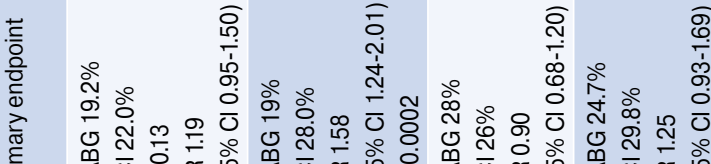

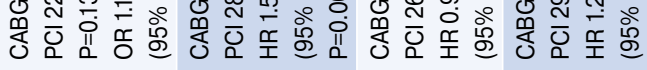

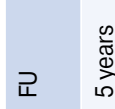

$\stackrel{\frac{\infty}{\pi}}{\stackrel{\infty}{\varpi}}$

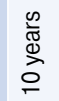

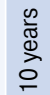

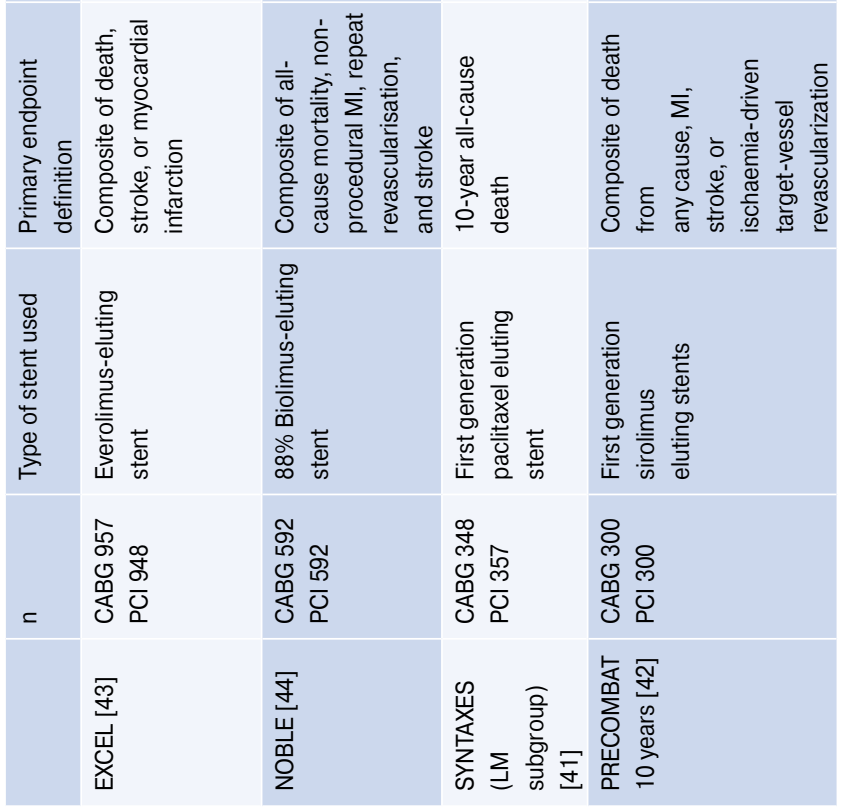


to DEFINITION criteria to provisional stenting vs. a systematic 2-stent technique. Target lesion failure (TLF) at 1-year follow-up was significantly higher in the provisional group mainly driven by an increase in target vessel MI and TLR without differences in cardiac death. No differences in stent thrombosis were observed between the two groups [54].

A network meta-analysis published this year evaluated outcomes of five different PCI techniques (provisional stenting, $\mathrm{T}$ stenting/T and protrusion, crush, culotte, and DK-crush) in patients with lesions involving coronary bifurcations. The study evaluated 21 RCT including 5711 patients. At a median follow-up of 12 months, DK-crush was associated with fewer MACE, driven by lower rates of repeat revascularization. Rates of cardiac death, MI, and stent thrombosis were not significantly different among techniques [55]. In the context of LMCAD involving the bifurcation, the need for final kissing balloon inflation is still debated. A large registry including 2742 patients treated with ultra-thin strut DES showed no differences in the composite endpoint (all-cause death, MI, TLR, and stent thrombosis) between patients treated with final kissing balloon or not. However, in LMCAD involving the bifurcation treated with two stents, the use of final kissing balloon was associated with less restenosis and TVR [56]. In contrast, a sub-analysis of the EXCEL trial showed no differences in events at 4-year follow-up between patients treated with and patients treated without final kissing balloon inflation in both one and two stent groups [57].

Restenosis and small vessel disease. Several studies have focused on the treatment of small coronary vessels assessing the performance of different devices in this lesion subset. A study from the SCAAR registry including 14788 patients with small vessels $(<2.5 \mathrm{~mm})$ treated with DES or drug-coated balloons (DCB) showed a higher rate of restenosis in the DCB group at 3-year follow-up with no differences in death, MI, or target lesion thrombosis [58]. A pooled analysis from the BIOFLOWII, IV, and VI trials compared the performance of an ultrathin-strut bioresorbable polymer sirolimusDES vs. durable-polymer everolimus-DES in small vessels $(<2.75 \mathrm{~mm})$ showing lower rates of TLF and target vessel MI in the biodegradable polymer sirolimus-DES group [59].

In the field of restenosis, the DAEDALUS study, a patient-level meta-analysis including 10 RCT, showed that treatment of in-stent restenosis (ISR) with DCB was associated with a higher risk of TLR at 3 years, with no differences in the safety outcome (death, MI, or target lesion thrombosis) [60]. A sub-analysis of this study, comparing BMS-ISR and DES-ISR, demonstrated that both treatment strategies (DCB and new DES implantation) were similarly effective and safe in patients with BMS-ISR. However, in patients with DES-ISR, treatment with DCB was associated with a higher rate of
TLR at 3 years and non-significant differences in safety outcomes [61].

Chronic total occlusions. Research in the field of chronic total occlusions (CTO) has focused largely on technical aspects and clinical benefit. The impact of CTO PCI on ischaemic burden was evaluated in a study in which patients underwent $(15 \mathrm{O}) \mathrm{H}_{2} \mathrm{O}$ positron emission tomography prior to and 3 months after successful CTO PCI. Results demonstrated a significant reduction in perfusion defect size after CTO PCI with significant improvement of the hyperaemic myocardial blood flow and coronary flow reserve within the CTO area [62]. The efficacy and safety of using saphenous vein grafts (SVG) for retrograde crossing during CTO PCI was explored in a study including 1615 retrograde CTO PCI. The use of the SVG for retrograde access was associated with higher rates of procedural success without differences in in-hospital MACE [63]. A comparison of available scores to predict CTO PCI success showed comparable capacity of the EuroCTO (CASTLE) and JCTO scores with a superior discriminatory capacity for CASTLE score as complexity increased [64]. A Japanese score to predict successful guidewire crossing through collaterals identified small vessel, reverse bend, and continuous bends as predictors of failure in septal collaterals, and small vessel, reverse bend, and corkscrew as predictors of failure in epicardial collaterals [65].

In the field of complex PCI, a registry from the British Cardiovascular Intervention Society demonstrated that patients who had PCI to their last remaining patent vessel had a higher risk profile (older age, more comorbidities, and higher prevalence of reduced LVEF) and had more clinical events than patients with more than one patent vessel. This was independent of the vessel treated [66].

\section{Interventional devices}

Durable-polymer, biodegradable polymer, and polymerfree drug-eluting stents. The 10-year results of the ISARTEST- 5 trial, including the $64 \%$ surviving patients of the initial 3000 patients enrolled, did not find any difference in outcomes between patients treated with polymer-free vs. durable polymer DES [67]. The incidence of stent thrombosis was low and comparable in both groups $(1.6 \%$ vs. $1.9 \%$ ) but, unfortunately, high rates of overall adverse clinical events were observed during this very long clinical follow-up. In the SORT-OUT 9 trial, 3151 patients were randomized to treatment with the Biofreedom ${ }^{\mathrm{TM}}$ stent (stainless steel drug-coated polymer-free stent) or the Orsiro $^{\mathrm{TM}}$ stent (ultrathin strut, biodegradable polymer, cobalt-chromium sirolimus eluting) [68]. The Biofreedom ${ }^{\mathrm{TM}}$ polymer-free stent did not meet the criteria for non-inferiority regarding major adverse cardiovascular events at 12 months in this all-comers population. The HOSTReduce-Polytech-ACS trial randomized over 3400 patients with ACS, known to carry a heightened risk of thrombosis and delayed healing after PCI, to a durable- 

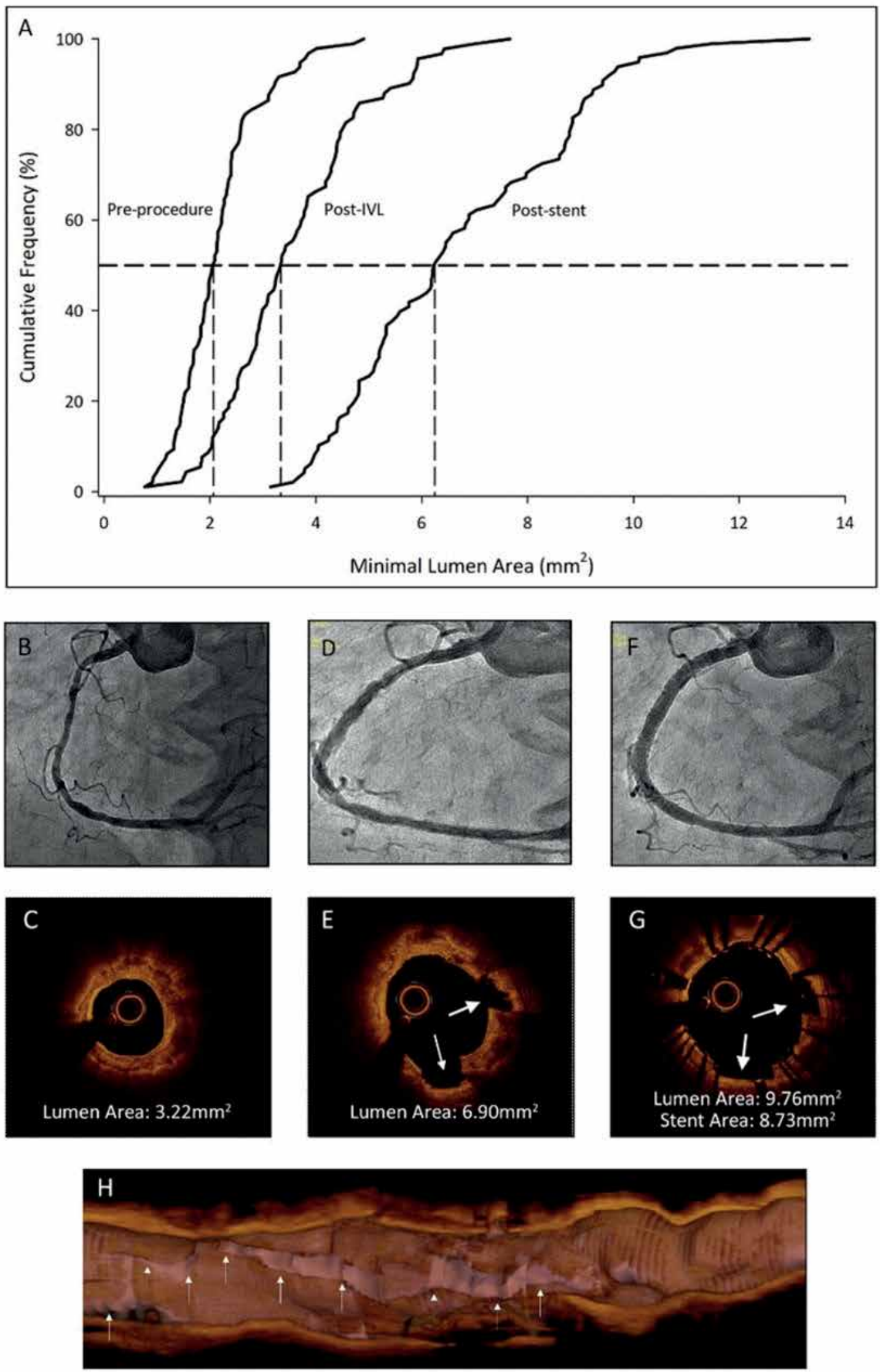

Figure 5. The Disrupt III study. (A) Changes in angiographic minimal lumen diameter. (B-H) Angiographic and optical coherence tomography images of a patient with a calcified lesion treated with IVL. Image obtained with permission from Hill et al. [77]. 
polymer DES or a biodegradable polymer stent [69]. There was no significant difference between the groups on the primary outcome measure (patient-oriented clinical outcome at 1 year). Nevertheless, the device-oriented clinical endpoint at 1-year was significantly lower in patients treated with the durable-polymer device. The PIONEER III trial tested the Supreme 'healing-targeted' HT-DES [a thin-strut ( $80 \mathrm{mg}$ ) DES with rapid sirolimus delivery and polymer degradation (4-6 weeks), plus a base layer that promotes endothelial migration] against the Xience ${ }^{\mathrm{TM}} /$ Promus $^{\mathrm{TM}}$ durable-polymer DES in 1632 all-comer patients [70]. At 12 months, TLF occurred in $5.4 \%$ of the HT-DES patients and on $5.1 \%$ of the durablepolymer DES patients, meting the trial criteria for noninferiority. The secondary endpoint of target-vessel MI was not significantly different between groups, although it tended to be lower for the HT-DES (3.4\% vs. $4.1 \%$; $\mathrm{P}=0.45$ ). These findings suggest that among the three components of DES, the platform (strut thickness and the stent design) might at least be as important as the drug and the polymer.

Drug-coated balloons. Despite the initial alarm created by the publication of a meta-analysis that suggested an increased mortality risk associated with paclitaxel containing devices in patients with peripheral arterial disease, another meta-analysis with patient-level data dissipated these safety concerns [71]. A meta-analysis focused on the coronary space including 4590 patients treated for either coronary ISR or de novo lesions did not find an increase in mortality in patients treated with paclitaxel-DCB [72]. In fact, at a 3-year follow-up, the risk of both all-cause (RR $0.73,95 \%$ CI $0.53-1.00$ ) and cardiac mortality (RR 0.53 , 95\% CI $0.33-0.85$ ) was significantly lower in those patients treated with DCB compared with alternative treatments. Likewise, another meta-analysis, which included 14 RCT with 2483 patients treated for 'de novo' lesions found no differences between DCB and alternative therapeutic modalities in terms of MACE, vessel thrombosis, or cardiovascular mortality [73]. However, DCB were associated with a lower incidence of MI (RR 0.48, 95\% CI 0.25-0.90) and allcause mortality (RR $0.45,95 \%$ CI $0.22-0.94$ ). Finally, the PICCOLETO II RCT recently compared DCB with everolimus-DES in 118 stable patients with de novo lesions in small vessels [74]. At 6 months, in-lesion late lumen loss (primary endpoint) was $0.17 \pm 0.39 \mathrm{~mm}$ in the everolimus-DES group and $0.04 \pm 0.28 \mathrm{~mm}$ in the DCB group, meeting the predefined non-inferiority criteria $(\mathrm{P}=0.03)$.

Thin-struts drug-eluting stents. At 3 years, the ultrathin-strut Orsiro ${ }^{\mathrm{TM}}$ stent maintained an advantage over the durable-polymer Xience ${ }^{\mathrm{TM}}$, according to the new data from the BIOFLOW V study. This study showed a $40 \%$ relative reduction in TLF as well as significantly lower rates of target-vessel MI, ischaemia-driven TLR, and late/very late stent thrombosis in the Orsiro ${ }^{\mathrm{TM}}$ arm
[75]. The 3-year clinical follow-up of the DESSOLVE III RCT confirmed the efficacy and safety of the ultrathinstrut biodegradable polymer MiStent sirolimus-eluting stent as compared to thin-strut permanent polymer Xience $^{\mathrm{TM}}$ stent [76]. The primary endpoint (a deviceoriented composite endpoint) occurred in $10.5 \%$ for MiStent ${ }^{\mathrm{TM}}$ sirolimus-eluting stent and $11.5 \%$ for $\mathrm{Xience}^{\mathrm{TM}}$ stent $(\mathrm{P}=0.55)$. A pooled analysis including 2337 patients with more complex coronary artery disease (moderate-tosevere calcification or small vessels) showed a reduction in TLF at 1 year favouring the ultrathin-strut Orsiro $^{\mathrm{TM}}$ stent in the small vessels cohort ( $8.0 \%$ vs. $12.4 \%$; $\mathrm{P}<0.01)$ [59].

Coronary intravascular lithotripsy. Intravascular lithotripsy (IVL) showed its usefulness to optimize PCI results in severely calcified lesions, with good safety and efficacy results at 30 days in the DISRUPT-CAD III study [77]. This single-arm prospective registry included 431 patients with severely calcified lesions (mean calcified segment length $47.9 \pm 18.8 \mathrm{~mm}$, calcium angle $292.5 \pm 76.5^{\circ}$ and calcium thickness $0.96 \pm 0.25 \mathrm{~mm}$ ), treated with IVL. Procedural success was $92.4 \%$ and a residual diameter stenosis $<30 \%$ was obtained in $99.5 \%$ of lesions (Figure 5). The primary safety endpoint, freedom from 30-day MACE, was observed in $92.2 \%$ of patients. Therefore, this technique emerges as a new attractive (easy to-use) therapeutic modality for patients with heavily calcified lesions.

Bare-metal stents. In patients with ACS, cobaltchromium-based TiNO-coated stents were non-inferior to platinum - chromium-based biodegradable polymer everolimus-DES for major cardiac events at 12 months (HR 0.93, 95\% CI 0.71-1.22, $\mathrm{P}<0.001$ for non-inferiority), and were superior for the co-primary endpoint of cardiac death, MI, and bleeding at 18 months, as shown in the TIDES-ACS randomized trial [78]. Despite the early superiority of everolimus-DES over BMS in STEMI patients, the 10-year results of the EXAMINATION trial demonstrated that, beyond 5 years, event rates were very low and similar with both stents [30]. No differences were found between everolimus-DES and BMS in terms of TLR and definite stent thrombosis between 5 and 10 years $(1.2 \%$ vs. $1.2 \%$; $\mathrm{P}=0.962 ; 0.5 \%$ vs. $0.1 \% ; \mathrm{P}=0.177$, respectively).

Bioresorbable scaffolds. The MAGSTEMI trial compared the in-stent/scaffold vasomotion (primary endpoint) between the magnesium-based bioresorbable scaffold (MgBRS) and a sirolimus-DES at 12-month follow-up in patients with STEMI [79]. Although MgBRS demonstrated a larger vasomotor response to pharmacological agents, they were associated with a lower angiographic efficacy and a higher need for TLR at 1 year ( $16.2 \%$ vs. $5.2 \% ; \mathrm{P}=0.030)$. The OCT sub-study of this trial showed that at 1-year follow-up, both the minimal lumen area (MLA) $\left(3.92\right.$ vs. $\left.6.31 \mathrm{~mm}^{2} ; \mathrm{P}<0.001\right)$ and the expansion index ( 0.58 vs. $0.86 ; \mathrm{P}<0.001)$ were smaller in patients treated with MgBRS [80]. Interestingly, half of 


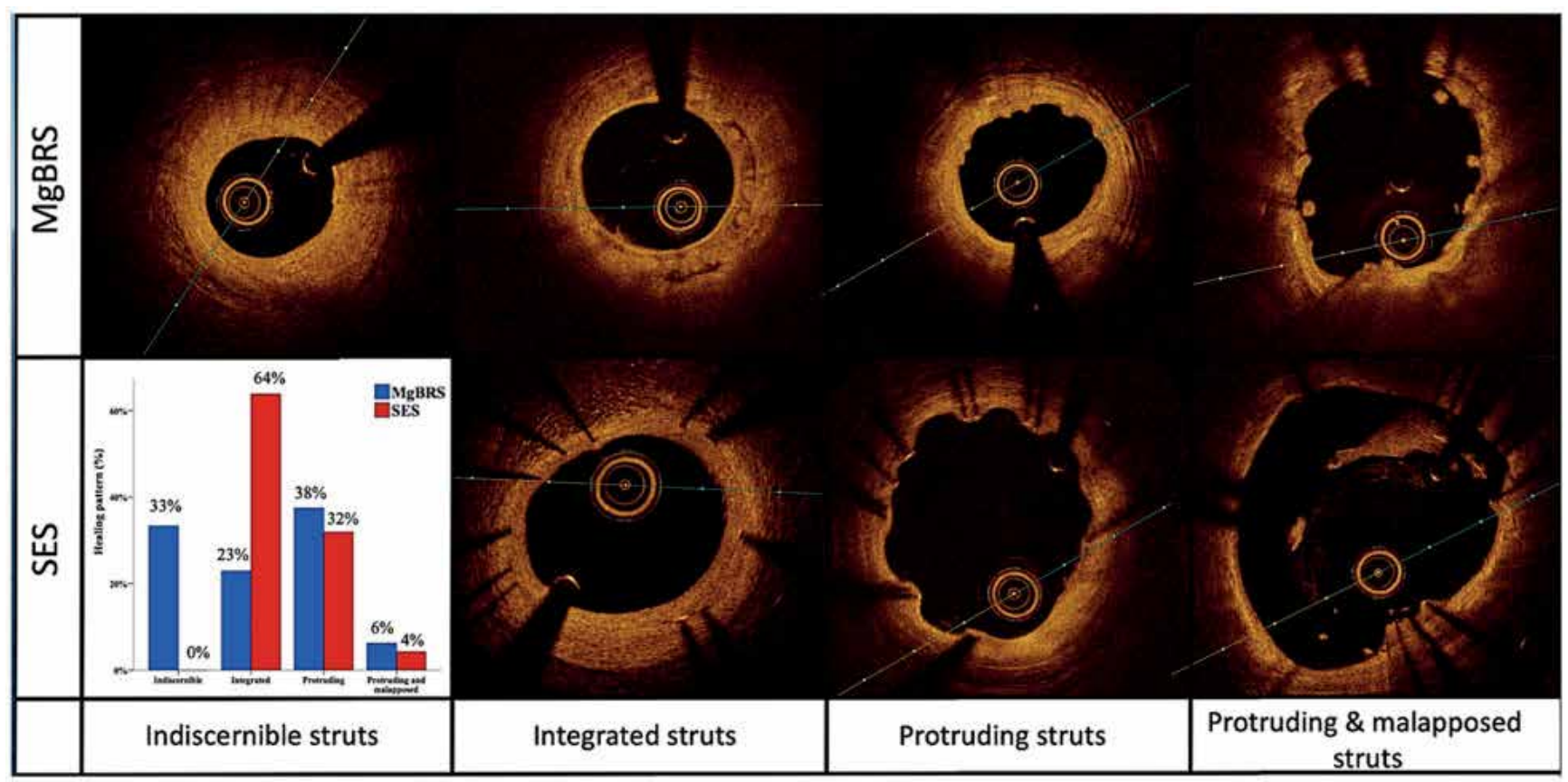

Figure 6. The OCT sub-study of the MagSTEMI trial. Comparative optical coherence findings of patients treated with magnesium bioresorbable scaffolds (MgBRS) and sirolimus-eluting stent (SES). Image obtained with permission from Gomez-Lara et al. [80].

the MgBRS restenosis was caused by scaffold collapse (Figure 6). In another OCT study that included 70 patients with MgBRS failure, the presence of late collapse was found as the main cause of late lumen loss, and device collapse was seen significantly more frequently in patients with fibrotic lesions [81]. These data suggest that future developments of MgBRS should focus on maintaining the radial force of the device for a longer period.

\section{Invasive diagnostic tools}

Intracoronary imaging. The long-term clinical followup of two large randomized trials evaluating the benefit of intravascular ultrasound (IVUS) use for PCI optimization was published this year. The IVUS-XPL trial randomized 1400 patients with long coronary lesions (implanted stent length $\geqslant 28 \mathrm{~mm}$ ) to receive IVUSguided or angiography-guided everolimus-DES. At 1 year, IVUS-guided stent implantation was associated with a significantly lower rate of MACE, mainly driven by the reduced risk for TVR. The trial showed a sustained benefit of the IVUS-guided strategy for up to 5 years and a landmark analysis demonstrated that differences in events between the two strategies not only accrued in the first year but also between the first and fifth year [82]. These results are in line with the 3-year follow-up of ULTIMATE, another RCT comparing angio and IVUS-guided second-generation DES implantation in an all-comer's population (1448 patients). At 3 years, the target vessel failure (TVF) rate was lower in the IVUSguided group, mainly driven by a reduction in the need for repeated revascularisations [83]. A patient-level metaanalysis of four randomised clinical trials of angiographic vs. IVUS-guided DES implantation (including 1396 patients) evaluated the effect of using IVUS before stent implantation on late outcomes. All patients underwent final IVUS-guided optimization after stent deployment. The authors demonstrated that the use of IVUS preintervention was associated with better procedural outcomes (larger minimum stent area), although no differences in clinical events were observed at 1-year follow-up [84].

The value of OCT to guide the management of angiographically intermediate coronary stenosis was assessed in a single-centre study that randomized patients to FFR or OCT imaging management. Criteria for treatment were FFR $<0.80$ in the physiology arm, and area stenosis $\geqslant 75 \%$, or $50-75 \%$ with minimal luminal area $<2.5 \mathrm{~mm}^{2}$ or plaque rupture, in the imaging arm. A total of 350 patients were randomized. The primary endpoint (composite of MACE or significant angina at 13 months) occurred significantly less frequently in the OCT-guided group. In the FFR arm, the rate of patients medically managed was higher and the total costs were lower [85].

The identification of vulnerable plaques still remains elusive and highly controversial. Several studies have been presented this year analysing the value of OCT to identify plaque characteristics related to the appearance of subsequent clinical events. The CLIMA study evaluated the predictive value of four high-risk plaque features as assessed by OCT, namely MLA $<3.5 \mathrm{~mm}^{2}$, fibrous cap thickness $<75 \mathrm{~mm}$, lipid arc circumferential extension $>180^{\circ}$, and presence of macrophages. A total of 1003 patients with an OCT pullback performed in the left anterior descending coronary artery were included. The 


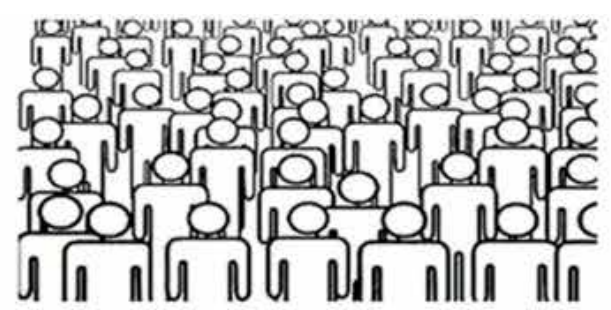

OCT LAD in 1003 patients with clinically indicated coronary angiogram from 11 independent centres enrolled from January 2013 to December 2016 (clinicaltrial.gov identifier NCTO2883088).
MLA $<3.5 \mathrm{~mm}^{2}$
$+\quad \underline{F C T}<75 \mu m$
$+\frac{\text { Lipid arc circumferential }}{\text { extension }>180^{\circ}}+\frac{\text { OCT defined }}{\text { macrophages }}$

In $18.9 \%$ of patients who experienced the primary end-point the combination of the 4 findings was an independent predictor of events (HR 7.54, Cl 95\% 3.1-18.6).
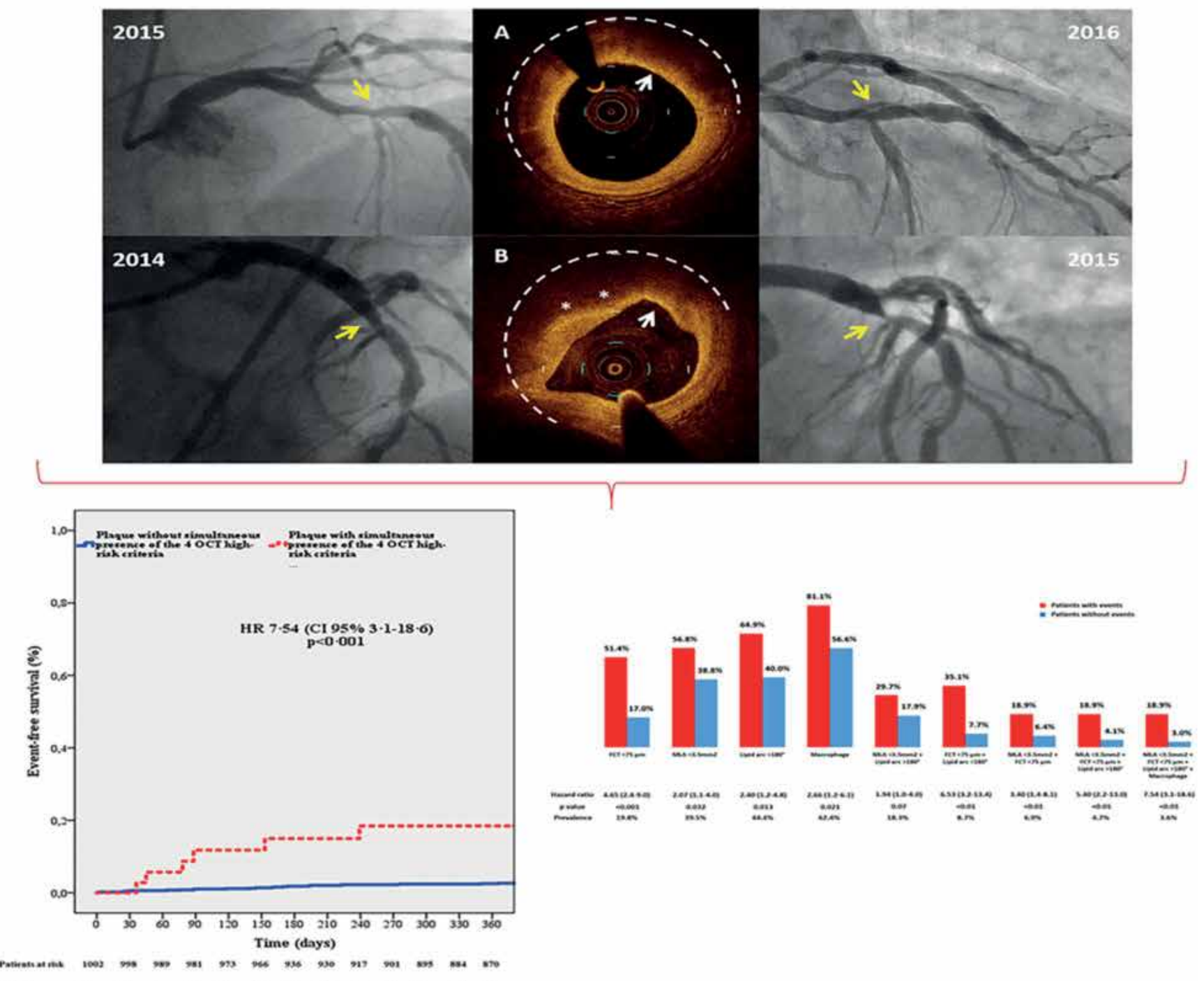

Figure 7. The CLIMA study. This prospective study explored the predictive value of multiple high-risk plaque features in the same coronary lesion [minimum lumen area (MLA), fibrous cap thickness (FCT), lipid arc circumferential extension, and presence of macrophages] as detected by optical coherence tomography (OCT) in 1003 patients undergoing OCT evaluation of the untreated proximal left anterior descending coronary artery. At 1 year, the pre-specified combination of plaque vulnerability features was an independent predictor of events. Image obtained with permission from Prati et al. [86]. 
primary endpoint was a composite of cardiac death and target segment MI at 1 year. The simultaneous presence of the four high-risk features in the same plaque was an independent predictor of adverse events in this population (Figure 7) [86]. The predictive value of OCT has been also assessed in the COMBINE trial, a natural history prospective study evaluating the incidence of MACE at 18 months in diabetic patients with FFR negative lesions according to the presence of a thin-cap fibroatheroma (TCFA) vs. non-TCFA morphology. OCT-defined TCFA was present in $\sim 25 \%$ of the FFR negative lesions and was a predictor of events at follow-up [87]. The OCT sub-study of the COMPLETE trial evaluated the morphological characteristics of non-culprit plaques in STEMI patients. The authors found that nearly half of the patients had an obstructive plaque with high-risk features. Interestingly, the presence of TCFA was more frequent in obstructive than in non-obstructive lesions. The association of lesion obstruction and vulnerability features might explain the better outcomes observed in patients randomized to the treatment of the non-culprit obstructive stenosis in the COMPLETE trial [88].

Regarding the use of other intracoronary imaging techniques to assess plaque characteristics, the PROSPECT II was a natural history study evaluating the predictive value of near infrared spectroscopy IVUS (IVUS-NIRS) in patients after an ACS. Following treatment of the culprit lesion, the proximal segments of the three coronary arteries were systematically assessed with IVUS-NIRS. Plaque burden $>70 \%$, MLA $<4.0$ $\mathrm{mm}^{2}$, and a high lipid core burden index were predictors of events at follow-up (median 3.7 years) [89]. A total of 182 patients (with angiographically mild and nonflow-limiting lesions and a plaque burden $>65 \%$ ), included in PROSPECT II were further randomized to medical treatment or bioresorbable vascular scaffold (BVS) implantation (in the PROSPECT ABSORB trial). At 25-month IVUS follow-up, the MLA was larger in lesions treated with BVS vs. those managed medically. Scaffold implantation in these lesions was safe with only one reported case of thrombosis and 1 case showing scaffold discontinuities. A favourable but nonsignificant trend towards 1-year plaque-related events was observed. The trial was, however, not powered for clinical endpoints and this concept needs to be examined in a larger study [89].

Coronary physiology. New data published this year have confirmed the safety of PCI deferral based on FFR. The J-CONFIRM Registry, from Japan, prospectively enrolled 1263 patients with 1447 lesions and showed a 2-year TVF rate of $5.5 \%$ in deferred lesions, highlighting the safety of this strategy [90]. A large registry evaluating patients with stable angina who underwent angiography between 2009 and 2017 demonstrated a progressive increase in the use of FFR and a lower risk of mortality at 1-year follow-up in patients with FFR-guided treatment vs. those managed based only on angiography [91]. In specific lesions subsets, a multicentre observational study evaluated the safety of LMCAD revascularization deferral based on iwFR. The study included 314 patients in whom LMCAD treatment was deferred $[n=163(51.9 \%)]$ or performed $[n=151(48.1 \%)]$ according to the iwFR cutoff $\leqslant 0.89$. There were no differences between the two groups in the composite of all-cause death, nonfatal MI, and ischaemia-driven TLR during a median followup of 30 months, suggesting the safety of using iwFR to determine the need for revascularization in patients with LMCAD [92]. Another field of intense research has been the use of physiology after PCI. The DEFINE PCI was a multicentre, prospective study in which a blinded iwFR pull-back was performed after an angiographically successful PCI. A total of 500 patients were evaluated showing an iwFR $<0.90$ after PCI in $24 \%$ of them. Of those with an abnormal iwFR post-PCI, $81.6 \%$ had focal stenosis potentially treatable with stent optimization or new stent implantation [93]. The 1-year follow-up results demonstrated that patients with iwFR $<0.95$ post-PCI had more events at follow-up (a composite of death, spontaneous MI, or clinically driven TVR) (HR 3.38; 95\% CI 0.99-11.6; log-rank $\mathrm{P}=0.04$ ) and less improvement in anginal symptoms [94].

\section{Adjunctive pharmacotherapy and high bleeding risk patients}

Two trials explored the effect of ticagrelor monotherapy on bleeding and ischaemic events in ACS patients undergoing PCI. TWILIGHTACS confirmed that dropping aspirin after 3 months of dual antiplatelet therapy (DAPT) with ticagrelor reduced bleeding risk by $53 \%$ without increasing the rate of ischaemic events [95]. Along the same line, the TICO randomized trial showed that switching to ticagrelor monotherapy after 3 months of DAPT reduced major bleeding without increasing ischaemic risk compared with 12 months of DAPT in ACS patients [96]. These findings indicate that ticagrelor monotherapy could be an optimal strategy, balancing both ischaemic and bleeding risks, for patients with ACS treated by PCI with second-generation DES. However, neither trial was powered to detect a difference in ischaemic events.

Results of two large prospective studies have consolidated the concept of a reduced DAPT duration with current-generation DES among patients at high risk for bleeding. In the ONYX-ONE trial, 1996 patients at high bleeding risk were randomly assigned to receive zotarolimus-DES or polymer-free DES [97]. After PCI, patients were treated with 1-month DAPT, followed by single antiplatelet therapy. At 1 year, the primary outcome was observed in $17 \%$ of patients in the zotarolimusDES group and in $17 \%$ in the polymer-free DES group, suggesting that among patients at high bleeding risk who received 1-month DAPT, use of polymer- 
based zotarolimus-DES was non-inferior to the use of polymer-free DES. Likewise, the XIENCE ShortDAPT program, including $\sim 3600$ patients, tested antiplatelet treatment duration of 1 month and 3 months. XIENCE 90, using 3-month DAPT, enrolled 2047 patients, and XIENCE 28, using 1-month DAPT, included 963 patients [98]. For XIENCE 28, the primary analysis period was between months 1 and 6. For XIENCE 90, outcomes were analysed between months 3 and 12. For comparative purposes, historical controls were drawn from the XIENCE V allcomers study, in which $91 \%$ of patients were on DAPT at 6 months and $85.6 \%$ at 1 year. XIENCE 90 participants had similar rates of all death or MI between 3 and 12 months compared with controls (5.4\% vs. 5.4\%; P for non-inferiority $=0.0063)$. XIENCE 28 also used controls for death/MI in the test group between 1 and 6 months (3.5\% vs. $4.5 \%$; P for noninferiority: 0.0005). Interestingly, major bleeding (BARC type 3 to 5) was less common in both XIENCE 90 and XIENCE 28, than in the XIENCE V historic cohort.

A network meta-analysis including 52816 patients with ACS observed that prasugrel and ticagrelor reduced ischaemic events and increased bleeding in comparison with clopidogrel. There was no efficacy or safety difference between prasugrel and ticagrelor [99]. A Korean randomized trial in ACS patients undergoing PCI showed that a prasugrel-based dose de-escalation strategy, starting 1 month after PCI, reduced the risk of net clinical outcomes up to 1 year, mainly driven by a reduction in bleeding without an increase in ischaemic events [100]. Regarding the optimal timing of $\mathrm{P} 2 \mathrm{Y}_{12}$ inhibitors administration, an RCT including 1449 ACS patients found no differences in clinical outcomes between a downstream and an upstream antiplatelet treatment strategy [101]. In the COMPARE CRUSH trial, 727 patients with STEMI were randomly assigned to $60 \mathrm{mg}$ crushed or whole prasugrel in addition to $500 \mathrm{mg}$ IV aspirin [102]. There were no differences, in TIMI 3 flow either in the infarct-related artery before PCI, or in the rates of complete ST-segment resolution at 1 hour after PCI. Although an enhanced degree of platelet inhibition was demonstrated in the group receiving crushed pills before primary PCI, this theoretical benefit failed to translate into clinically detectable reperfusion effects.

In patients aged 70 years or older presenting with NSTEMI-ACS, clopidogrel is a favourable alternative to ticagrelor, because it leads to fewer bleeding events without an increase in the combined endpoint of allcause death, MI, stroke, and bleeding, as observed in POPULAR AGE trial [103]. Moreover, an observational analysis of 14005 MI patients 80 years or older enrolled in the SWEDEHEART registry showed that, compared to clopidogrel, ticagrelor was associated with $17 \%$ and $48 \%$ higher risks of death (1.17, 95\% CI 1.03-1.32) and bleeding $(1.48,95 \%$ CI $1.25-1.76)$, but a lower risk of MI $(0.80,95 \%$ CI $0.70-0.92)$ and stroke $(0.72,95 \%$ CI
0.56-0.93) [104]. Therefore, clopidogrel appears to be an interesting $\mathrm{P}_{2} \mathrm{Y}_{12}$ inhibitor alternative for elderly patients with a higher bleeding risk. The One-Month DAPT randomized trial tested if 1 month of aspirin plus a P2Y $Y_{12}$ inhibitor followed by aspirin monotherapy would be noninferior to the standard regimen of 6-12 months of DAPT for the composite endpoint of cardiovascular events or major bleeding at 1 year [105]. In the 1-month DAPT group, composite events occurred in $5.9 \%$ of patients vs. $6.5 \%$ of the 6 - to 12 -month DAPT group. The HR for the 1-month DAPT therapy followed by aspirin monotherapy was $0.9, \mathrm{P}<0.001$ for non-inferiority compared to the recommended 6-12 months of DAPT therapy. The COMPASS-PCI, a sub-study of COMPASS trial, included 9862 patients who underwent PCI for chronic coronary syndrome $>1$ year earlier (average time 5.4 years) to aspirin plus rivaroxaban vs. aspirin alone. The study demonstrated that rivaroxaban $2.5 \mathrm{mg}$ twice daily plus aspirin reduced MACE rate (cardiovascular death, MI, or stroke) and all-cause mortality, but increased major bleeding as compared with aspirin alone [106]. Interestingly, among those patients with previous PCI, the effects on MACE and mortality were consistent irrespective of the time elapsed since the last PCI. Finally, the ALPHEUS trial found that ticagrelor was not superior to clopidogrel in reducing periprocedural myocardial necrosis in stable coronary patients undergoing high-risk elective PCI but caused an increase in minor bleeding at 30 days [107].

\section{Conclusions}

Last year, the first report from the ESC/EAPCI ATLAS project disclosed considerable international heterogeneity in PCI volumes that was closely related to gross national income per capita [108, 109]. Major efforts should be made by scientific societies (including ESC and EAPCI) focusing on all implicated stakeholders to address these equity gaps. Likewise, in the year 2020, the pandemic strikingly disrupted clinical care of patients with cardiovascular diseases and, particularly, those with CAD. Currently, we are enduring the 'third wave' of COVID-19 while getting ready for future threats. Resilience will remain paramount to face these complex novel scenarios. This paper highlights that the field of interventional cardiology continues to evolve each year. However, major care should be taken to preserve academic endeavour in these challenging times and to ensure that continuous scientific research efforts, as those reported in this review, will be maintained in order to advance our knowledge on prevention, diagnosis, and management of patients with CAD, eventually leading to improved clinical outcomes.

Conflict of interest: Nieves Gonzalo: speaker at educational events for Abbott and Boston Scientific. Other authors have nothing to declare. 


\section{References}

1. Lombardi CM, Carubelli V, lorio A, et al. Association of troponin levels with mortality in Italian patients hospitalized with coronavirus disease 2019: results of a multicenter study. JAMA Cardiol. 2020;5:1274-80.

2. Shi S, Qin M, Cai $Y$, et al. Characteristics and clinical significance of myocardial injury in patients with severe coronavirus disease 2019. Eur Heart J. 2020; 41:2070-9.

3. Peretto G, Sala S, Caforio ALP. Acute myocardial injury, MINOCA, or myocarditis? Improving characterization of coronavirus-associated myocardial involvement. Eur Heart J. 2020;41:2124-5.

4. Basso C, Leone O, Rizzo S, et al. Pathological features of COVID-19-associated myocardial injury: a multicentre cardiovascular pathology study. Eur Heart J. 2020;41:3827-35.

5. Inciardi RM, Adamo M, Lupi L, et al. Characteristics and outcomes of patients hospitalized for COVID-19 and cardiac disease in Northern Italy. Eur Heart J. 2020;41:1821-9.

6. Fernandez Gasso L, Maneiro Melon NM, Sarnago Cebada F, et al. Multivessel spontaneous coronary artery dissection presenting in a patient with severe acute SARS-CoV-2 respiratory infection. Eur Heart J. 2020;41:3100-101.

7. Meyer P, Degrauwe S, Van Delden C, et al. Typical takotsubo syndrome triggered by SARSCoV-2 infection. Eur Heart J. 2020;41:1860.

8. Rivero F, Antuňa $P$, Cuesta J, Alfonso F. Severe coronary spasm in a COVID-19 patient. Catheter Cardiovasc Interv. 2020; doi:10.1002/ccd.29056.

9. Bangalore S, Sharma A, Slotwiner A, et al. ST-segment elevation in patients with COVID$19-$ a case series. N Engl J Med. 2020;382:2478-80.

10. Nadkarni GN, Lala A, Bagiella E, et al. Anticoagulation, bleeding, mortality, and pathology in hospitalized patients with COVID-19. J Am Coll Cardiol. 2020;76:1815-26.

11. Choudry FA, Hamshere SM, Rathod KS, et al. High thrombus burden in patients with COVID-19 presenting with ST-segment elevation myocardial infarction. J Am Coll Cardiol. 2020;76:1168-76

12. Said K, El-Baghdady $\mathrm{Y}$, Abdel-Ghany M. Acute coronary syndromes in developing countries during the COVID-19 pandemic. Eur Heart J. 2020;41:2518-21.

13. Pessoa-Amorim G, Camm CF, Gajendragadkar $P$, et al. Admission of patients with STEMI since the outbreak of the COVID-19 pandemic: a survey by the European Society of Cardiology. Eur Heart J Qual Care Clin Outcomes. 2020;6:210-6.

14. Mahmud E, Dauerman HL, Welt FGP, et al. Management of acute myocardial infarction during the COVID-19 pandemic: a position statement from the Society for Cardiovascular Angiography and Interventions (SCAI), the American College of Cardiology (ACC), and the American College of Emergency Physicians (ACEP). J Am Coll Cardiol. 2020;76:1375-84.

15. Baldi E, Sechi GM, Mare C, et al.; Lombardia CARe researchers. COVID-19 kills at home: the close relationship between the epidemic and the increase of out-of-hospital cardiac arrests. Eur Heart J. 2020;41:3045-54.

16. Rodriguez-Leor O, Cid-Alvarez B, Ojeda S, et al. Impact of the COVID-19 pandemic on interventional cardiology activity in Spain. REC Interv Cardiol. 2020;2:82-9.

17. De Luca G, Verdoia M, Cercek M, et al. Impact of COVID-19 pandemic on mechanical reperfusion for patients with STEMI. J Am Coll Cardiol. 2020;76:2321-30.

18. De Rosa S, Spaccarotella C, Basso C, et al.; Societá Italiana di Cardiologia and the CCU Academy investigators group. Reduction of hospitalizations for myocardial infarction in Italy in the COVID-19 era. Eur Heart J. 2020;41:2083-8.

19. Mafham MM, Spata E, Goldacre R, et al. COVID-19 pandemic and admission rates for and management of acute coronary syndromes in England. Lancet. 2020;396:381-9.

20. Chieffo A, Stefanini GG, Price S, et al. EAPCl position statement on invasive management of acute coronary syndromes during the COVID-19 pandemic. Eur Heart J. 2020;41:1839-51.

21. Maron DJ, Hochman JS, Reynolds HR, et al. Initial invasive or conservative strategy for stable coronary disease. N Engl J Med. 2020;382:1395-407.

22. Spertus JA, Jones PG, Maron DJ, et al. Health-status outcomes with invasive or conservative care in coronary disease. N Engl J Med. 2020;382:1408-19.

23. Bangalore S, Maron DJ, O'Brien SM, et al.; ISCHEMIA-CKD Research Group. Management of coronary disease in patients with advanced kidney disease. N Engl J Med. 2020;382:1608-18.

24. Bangalore S, Maron DJ, Stone GW, Hochman JS. Routine revascularization versus initial medical therapy for stable ischemic heart disease: a systematic review and meta-analysis of randomized trials. Circulation. 2020;142:841-57.

25. Knuuti J, Wijns W, Saraste A, et al.; ESC Scientific Document Group. 2019 ESC Guidelines for the diagnosis and management of chronic coronary syndromes. Eur Heart J. 2020;41:407-77.

26. Konigstein M, Giannini F, Banai S. The Reducer device in patients with angina pectoris: mechanisms, indications, and perspectives. Eur Heart J. 2018;39:925-33.

27. Kunadian V, Chieffo A, Camici PG, et al. EAPCl expert consensus document on ischaemia with non-obstructive coronary arteries in collaboration with European Society of Cardiology Working Group on Coronary Pathophysiology \& Microcirculation Endorsed by Coronary Vasomotor Disorders Internati. Eur Heart J. 2020;41:3504-20.

28. Reynolds HR, Maehara A, Kwong Ry Sedlak T, et al. Coronary optical coherence tomography and cardiac magnetic resonance imaging to determine underlying causes of MINOCA in women. Circulation. 2020; doi:10.1161/CIRCULATIONAHA.120.052008.
29. Collet JP, Thiele H, Barbato E, et al.; ESC Scientific Document Group. 2020 ESC Guidelines for the management of acute coronary syndromes in patients presenting without persistent ST-segment elevation. Eur Heart J. 2020; doi:10.1093/eurheartj/ ehaa575.

30. Brugaletta S. Everolimus-eluting stent versus bare-metal stent in ST-segment elevation myocardial infarction: 10-year follow-up of the multicenter randomized controlled EXAMINATION trial. Cardiovascular Therapeutics annual scientific symposium 2020. 15 October 2020.

31. Lemkes JS, Janssens GN, van der Hoeven NW, et al. Timing of revascularization in patients with transient ST-segment elevation myocardial infarction: a randomized clinical trial. Eur Heart J. 2019;40:283-91.

32. Kaura A, Sterne JAC, Trickey A, et al. Invasive versus non-invasive management of older patients with non-ST elevation myocardial infarction (SENIOR-NSTEMI): a cohort study based on routine clinical data. Lancet. 2020;396:623-34.

33. Atti V, Gwon Y, Narayanan MA, et al. Multivessel versus culprit-only revascularization in STEMI and multivessel coronary artery disease: meta-analysis of randomized trials. JACC Cardiovasc Interv. 2020;13:1571-82.

34. Kim MC, Hyun JY, Ahn Y, et al. Optimal revascularization strategy in non-ST-segmentelevation myocardial infarction with multivessel coronary artery disease: culprit-only versus one-stage versus multistage revascularization. J Am Heart Assoc. 2020;9:e016575.

35. Lemkes JS, Janssens GN, van der Hoeven NW, et al. Coronary angiography after cardiac arrest without ST segment elevation: one-year outcomes of the COACT randomized clinical trial. JAMA Cardiol. 2020;5:1-8.

36. Bougouin W, Dumas F, Lamhaut L, et al.; the Sudden Death Expertise Center investigators. Extracorporeal cardiopulmonary resuscitation in out-of-hospital cardiac arrest: a registry study. Eur Heart J. 2020;41:1961-71.

37. Kuno $T$, Takagi $H$, Ando $T$, et al. Safety and efficacy of mechanical circulatory support with Impella or intra-aortic balloon pump for high-risk percutaneous coronary intervention and/or cardiogenic shock: Insights from a network meta-analysis of randomized trials. Catheter Cardiovasc Interv. 2020; doi:10.1002/ccd.29236.

38. Siannaccone M, Albani S, Giannini F, et al. Short-term outcomes of Impella in cardiogenic shock: a review and meta-analysis of observational studies. Int J Cardiol. 2020; doi:10.1016/j.jijcard.2020.09.044.

39. Lemor A, Hosseini Dehkordi SH, Basir MB, et al. Impella versus extracorporeal membrane oxygenation for acute myocardial infarction cardiogenic shock. Cardiovasc Revasc Med. 2020;21:1465-71.

40. Schrage B, Becher PM, Bernhardt A, et al. Left ventricular unloading is associated with lower mortality in cardiogenic shock patients treated with veno-arterial extracorporeal membrane oxygenation: results from an international, multicenter cohort study. Circulation. 2020;142:2095-106.

41. Thuijs DJFM, Kappetein AP, Serruys PW, et al. Percutaneous coronary intervention versus coronary artery bypass grafting in patients with three-vessel or left main coronary artery disease: 10-year follow-up of the multicentre randomised controlled SYNTAX trial. Lancet. 2019;394:1325-34.

42. Park D-W, Ahn J-M, Park H, et al.; On behalf of the PRECOMBAT Investigators. Tenyear outcomes after drug-eluting stents versus coronary artery bypass grafting for left main coronary disease: extended follow-up of the PRECOMBAT trial. Circulation. 2020;141:1437-46.

43. Stone GW, Kappetein AP, Sabik JF, et al.; EXCEL Trial Investigators. Five-year outcomes after PCl or CABG for left main coronary disease. N Engl J Med. 2019;381:1820-30.

44. Holm NR, Mäkikallio T, Lindsay MM, et al. Percutaneous coronary angioplasty versus coronary artery bypass grafting in the treatment of unprotected left main stenosis: updated 5-year outcomes from the randomised, noninferiority NOBLE trial. Lancet. 2020;395:191-9.

45. D'Ascenzo F, De Filippo O, Elia E, et al. Percutaneous vs. surgical revascularization for patients with unprotected left main stenosis: a metaanalysis of 5-year follow-up randomized controlled trials. Eur Heart J Qual Care Clin Outcomes. 2020; doi:10.1093/ ehjqcco/qcaa041.

46. Gallo M, Blitzer D, Laforgia PL, et al. Percutaneous coronary intervention versus coronary artery bypass graft for left main coronary artery disease: a meta-analysis. J Thorac Cardiovasc Surg. 2020; doi:10.1016/j.jtcvs.2020.04.010.

47. Ahmad Y, Howard JP, Arnold AD, et al. Mortality after drug-eluting stents vs. coronary artery bypass grafting for left main coronary artery disease: a meta-analysis of randomized controlled trials. Eur Heart J. 2020;41:3228-35.

48. Gregson J, Stone GW, Ben-Yehuda O, et al. Implications of alternative definitions of peri-procedural myocardial infarction after coronary revascularization. J Am Coll Cardiol. 2020;76:1609-21.

49. Giustino G, Serruys PW, Sabik JF, et al. Mortality after repeat revascularization following PCI or CABG for left main disease: the EXCEL trial. JACC Cardiovasc Interv. 2020;13:375-87.

50. Thuijs DJFM, Milojevic M, Stone GW, et al. Impact of left ventricular ejection fraction on clinical outcomes after left main coronary artery revascularization: results from the randomized EXCEL trial. Eur J Heart Fail. 2020;22:871-9. 
51. Wiebe $\mathrm{J}$, Kuna $\mathrm{C}$, Ibrahim $\mathrm{T}$, et al. Long-term prognostic impact of restenosis of the unprotected left main coronary artery requiring repeat revascularization. JACC CardiovasC Interv. 2020;13:2266-74

52. Park S, Ahn J-M, Kim TO, et al. Revascularization in patients with left main coronary artery disease and left ventricular dysfunction. J Am Coll Cardiol. 2020;76:1395-406.

53. Tam DY, Dharma C, Rocha R, et al. Long-term survival after surgical or percutaneous revascularization in patients with diabetes and multivessel coronary disease. J Am Coll Cardiol. 2020;76:1153-64.

54. Zhang JJ, Ye F, Xu K, et al. Multicentre, randomized comparison of two-stent and provisional stenting techniques in patients with complex coronary bifurcation lesions: the DEFINITION II trial. Eur Heart J. 2020;41:2523-36.

55. Gioia G, Di Sonck J, Ferenc M, et al. Clinical outcomes following coronary bifurcation PC techniques: a systematic review and network meta-analysis comprising 5,711 patients. JACC Cardiovasc Interv. 2020;13:1432-44.

56. Gaido L, D'Ascenzo F, Imori Y, et al. Impact of kissing balloon in patients treated with ultrathin stents for left main lesions and bifurcations: an analysis from the RAINCARDIOGROUP VII study. Circ Cardiovasc Interv. 2020;13:e008325

57. Kini AS, Dangas GD, Baber $U$, et al. Influence of final kissing balloon inflation on long-term outcomes after $\mathrm{PCl}$ of distal left main bifurcation lesions in the EXCEL trial. Eurolntervention. 2020;16:218-24

58. Silverio A, Buccheri S, Venetsanos D, et al. Percutaneous treatment and outcomes of smal coronary vessels: a SCAAR report. JACC Cardiovasc Interv. 2020;13:793-804.

59. Dan K, Garcia-Garcia HM, Kolm P, et al. Comparison of ultrathin, bioresorbable-polymer sirolimus-eluting stents and thin, durable-polymer everolimus-eluting stents in calcified or small vessel lesions. Circ Cardiovasc Interv. 2020;13:e009189.

60. Giacoppo D, Alfonso F, Xu B, et al. Paclitaxelcoated balloon angioplasty vs. drug-eluting stenting for the treatment of coronary in-stent restenosis: a comprehensive, collaborative, individual patient data meta-analysis of 10 randomized clinical trials (DAEDALUS study). Eur Heart J. 2020;41:3715-28.

61. Giacoppo D, Alfonso F, Xu B, et al. Drug-coated balloon angioplasty versus drugeluting stent implantation in patients with coronary stent restenosis. J Am Coll Cardiol. 2020;75:2664-78.

62. Schumacher SP, Kockx M, Stuijfzand WJ, et al. Ischaemic burden and changes in absolute myocardial perfusion after chronic total occlusion percutaneous coronary intervention. Eurolntervention. 2020;16:e462-e471.

63. Xenogiannis I, Gkargkoulas F, Karmpaliotis D, et al. Retrograde chronic total occlusion percutaneous coronary intervention via saphenous vein graft. JACC Cardiovasc Interv. 2020;13:517-26

64. Kalogeropoulos AS, Alsanjari O, Keeble TR, et al. CASTLE score versus J-CTO score for the prediction of technical success in chronic total occlusion percutaneous revascularisation. Eurolntervention. 2020;15:e1615-e1623.

65. Nagamatsu W, Tsuchikane E, Oikawa Y, et al. Successful guidewire crossing via collateral channel at retrograde percutaneous coronary intervention for chronic total occlusion: the J-Channel score. Eurolntervention. 2020;15:e1624-e1632.

66. Shoaib A, Rashid M, Kontopantelis E, et al. Clinical characteristics and outcomes from percutaneous coronary intervention of last remaining coronary artery: an analysis from the British Cardiovascular Intervention Society Database. Circ Cardiovasc Interv. 2020;13:e009049.

67. Kufner S, Ernst M, Cassese S, et al.; ISAR-TEST-5 Investigators. 10-year outcomes from a randomized trial of polymer-free versus durable polymer drug-eluting coronary stents. J Am Coll Cardiol. 2020;76:146-58.

68. Jensen LO, Maeng M, Raungaard B, et al.; Sort Out IX Study Group. Randomized comparison of the polymer-free biolimus-coated biofreedom stent with the ultrathin strut biodegradable polymer sirolimus-eluting orsiro stent in an all-comers population treated with percutaneous coronary intervention: the SORT OUT IX trial. Circulation. 2020;141:2052-63.

69. Kim HS, Kang J, Hwang D, et al.; HOST-REDUCEPOLYTECH-ACS Randomized Clinical Trial Investigators. Durable polymer versus biodegradable polymer drug-eluting stents after percutaneous coronary intervention in patients with acute coronary syndrome: the HOST-REDUCEPOLYTECH-ACS trial. Circulation. 2020; doi:10.1161/ CIRCULATIONAHA.120.051700.

70. DES with synchronized antiproliferative drug delivery to target smooth muscle cell proliferation after DES implantation in coronary artery disease. Primary results of the PIONEER III Trial. American Heart Association Scientific Sessions 2020. 15 November 2020.

71. Rocha-Singh KJ, Duval S, Jaff MR, et al.; On behalf of VIVA Physicians, Inc. Mortality and paclitaxel-coated devices: an individual patient data meta-analysis. Circulation. 2020;141:1859-69.

72. Scheller B, Vukadinovic D, Jeger R, et al. Survival after coronary revascularization with paclitaxel-coated balloons. J Am Coll Cardiol. 2020;75:1017-28.

73. Elgendy IY, Gad MM, Elgendy AY, et al. Clinical and angiographic outcomes with drugcoated balloons for de novo coronary lesions: a meta-analysis of randomized clinical trials. J Am Heart Assoc. 2020;9:e016224.

74. Cortese B, Di Palma G, Guimaraes MG, et al. Drug-coated balloon versus drug eluting stent for small coronary vessel disease: PICCOLETO II randomized clinical trial. JACC Cardiovasc Interv. 2020;13:2840-9.
75. Kandzari DE, Koolen JJ, Doros G, et al.; BIOFLOW V Investigators. Ultrathin bioresorbablepolymer sirolimus-eluting stents versus thin durable-polymer everolimus-eluting stents for coronary revascularization: 3-year outcomes from the randomized BIOFLOW V trial. JACC Cardiovasc Interv. 2020;13:1343-53.

76. Takahashi K, Serruys PW, Kogame N, et al. Final 3-year outcomes of MiStent Biodegradable Polymer Crystalline Sirolimus-Eluting Stent Versus Xience Permanent Polymer Everolimus-Eluting Stent: insights from the DESSOLVE III All-Comers Randomized Trial. Circ Cardiovasc Interv. 2020;13:e008737.

77. Hill JM, Kereiakes DJ, Shlofmitz RA, et al. Intravascular lithotripsy for treatment of severely calcified coronary artery disease: the Disrupt CAD III study. J Am Coll Cardiol. 2020;76:2635-46

78. Tonino PAL, Pijls NHJ, Collet $\mathrm{C}$, et al.; TIDES-ACS Study Group. Titanium-nitrideoxidecoated versus everolimus-eluting stents in acute coronary syndrome: the Randomized TIDES-ACS trial. JACC Cardiovasc Interv. 2020;13:1697-705.

79. Sabaté $\mathrm{M}$, Alfonso $\mathrm{F}$, Cequier $\mathrm{A}$, et al. Magnesium-based resorbable scaffold versus permanent metallic sirolimus-eluting stent in patients with ST-segment elevation myocardial infarction: the MAGSTEMI Randomized Clinical Trial. Circulation. 2019;140:1904-16.

80. Gomez-Lara J, Ortega-Paz L, Brugaletta S, et al., Collaborators. Bioresorbable scaffolds versus permanent sirolimus-eluting stents in patients with ST-Segment Elevation Myocardial Infarction: vascular healing outcomes from the MAGSTEMI trial. Eurolntervention. 2020;16:e913-e921.

81. Ueki $Y$, Räber L, Otsuka T, et al. Mechanism of drug eluting absorbable metal scaffold restenosis: a serial optical coherence tomography study. Circ Cardiovasc Interv. 2020;13:e008657.

82. Hong S-J, Mintz GS, Ahn C-M, et al. Effect of intravascular ultrasound-guided drug-eluting stent implantation: 5 -year follow up of the IVUS-XPL Randomized trial. JACC CardiovasC Interv. 2020;13:62-71.

83. Gao X-F, Ge Z, Kong X-Q, et al.; ULTIMATE Investigators. Three-year outcomes of the ULTIMATE trial comparing intravascular ultrasound versus angiography-guided drugeluting stent implantation. J Am Coll Cardiol Cardiovasc Interv. 2020; doi:10.1016/j. jcin.2020.10.001.

84. Hong SJ, Kim D, Kim BK, et al. Acute and one-year clinical outcomes of pre-stenting intravascular ultrasound: a patient-level meta-analysis of randomised clinical trials. Eurolntervention. 2020; doi:10.4244/ElJ-D-20-00276.

85. Burzotta F, Leone AM, Aurigemma C, et al. Fractional flow reserve or optical coherence tomography to guide management of angiographically intermediate coronary stenosis: a single-center trial. JACC Cardiovasc Interv. 2020;13:49-58.

86. Prati $F$, Romagnoli $E$, Gatto $L$, et al. Relationship between coronary plaque morphology of the left anterior descending artery and 12 months clinical outcome: the CLIMA study. Eur Heart J. 2020;41:383-91.

87. Kedhi E. Combined optical coherence tomography and fractional flow reserve assessment to better predict adverse event outcomes in DM patients. Presented at: TCT 2020. 14 October 2020

88. Pinilla-Echeverri N, Mehta SR, Wang J, et al. Nonculprit lesion plaque morphology in patients with ST-segment-elevation myocardial infarction: results from the COMPLETE Trial Optical Coherence Tomography Substudys. Circ Cardiovasc Interv. 2020;13:e008768.

89. Stone GW, Maehara A, Ali ZA et al.; PROSPECT ABSORB Investigators. Percutaneous coronary intervention for vulnerable coronary atherosclerotic plaque. J Am Coll Cardiol. 2020;76:2289-301.

90. Kuramitsu S, Matsuo H, Shinozaki T, et al. Two-year outcomes after deferral of revascularization based on fractional flow reserve: the J-CONFIRM Registry. Circ Cardiovasc Interv. 2020;13:e009049.

91. Parikh RV, Liu G, Plomondon ME, et al. Utilization and outcomes of measuring fractional flow reserve in patients with stable ischemic heart disease. J Am Coll Cardiol. 2020;75:409-19.

92. Warisawa T, Cook CM, Rajkumar C, et al. Safety of revascularization deferral of left main stenosis based on instantaneous wave free ratio evaluation. JACC Cardiovasc Interv. 2020;13:1655-64

93. Jeremias A, Davies JE, Maehara A, et al. Blinded physiological assessment of residual ischemia after successful angiographic percutaneous coronary intervention: the DEFINE $\mathrm{PCl}$ study. JACC Cardiovasc Interv. 2019;12:1991-2001.

94. Patel M, Jeremias A, Davies J. One-year outcomes of patients with residual physiologic ischemia after percutaneous coronary intervention: the DEFINE PCI trial. Cardiovascular Therapeutics annual scientific symposium 2020. 15 October 2020.

95. Baber U, Dangas G, Angiolillo DJ, et al. Ticagrelor alone vs. ticagrelor plus aspirin following percutaneous coronary intervention in patients with non-ST-segment elevation acute coronary syndromes: TWILIGHT-ACS. Eur Heart J. 2020;41:3533-45.

96. Kim BK, Hong SJ, Cho YH, et al.; TICO Investigators. Effect of ticagrelor monotherapy vs ticagrelor with aspirin on major bleeding and cardiovascular events in patients with acute coronary syndrome: the TICO Randomized Clinical Trial. JAMA. 2020;323:2407-16.

97. Windecker S, Latib A, Kedhi E, et al.; ONYX ONE Investigators. Polymer-based or polymerfree stents in patients at high bleeding risk. N Engl J Med. 2020;382:1208-18.

98. Mehran R. The XIENCE Short DAPT Program: XIENCE 90/28 evaluating the safety of 3- and 1-month DAPT in HBR patients. Transcatheter Cardiovascular Therapeutics annual scientific symposium 2020. 15 October 2020. 
99. Navarese EP, Khan SU, Kołodziejczak M, et al. Comparative efficacy and safety of oral P2Y ${ }_{12}$ inhibitors in acute coronary syndrome: network meta-analysis of 52816 patients from 12 randomized trials. Circulation 2020;142:150-60.

100. Kim HS, Kang J, Hwang D, et al.; HOST-REDUCE-POLYTECHACS investigators. Prasugrel-based de-escalation of dual antiplatelet therapy after percutaneous coronary intervention in patients with acute coronary syndrome (HOST-REDUCEPOLYTECH-ACS): an open-label, multicentre, noninferiority randomised trial. Lancet. 2020;396:1079-89.

101. Tarantini G, Mojoli M, Varbella F, et al.; DUBIUS Investigators, on behalf of the Italian Society of Interventional Cardiology (SICI-GISE). Timing of oral $\mathrm{P}_{2} \mathrm{Y}_{12}$ inhibitor administration in non-ST elevation acute coronary syndrome. J Am Coll Cardiol. 2020;76:2450-9.

102. Vlachojannis GJ, Wilschut JM, Vogel RF, et al. COMPARE CRUSH: a randomized trial of prehospital crushed vs uncrushed prasugrel in STEMI. Circulation. 2020;142:2316-28.

103. Gimbel M, Qaderdan K, Willemsen L, et al. Clopidogrel versus ticagrelor or prasugrel in patients aged 70 years or older with non-ST elevation acute coronary syndrome (POPular AGE): the randomised, open label, non-inferiority trial. Lancet. 2020;395:1374-81.
104. Szummer K, Montez-Rath ME, Alfredsson J, et al. Comparison between ticagrelor and clopidogrel in elderly patients with an acute coronary syndrome: insights from the SWEDEHEART Registry. Circulation. 2020;142:1700-8.

105. Hong MK. One-month dual antiplatelet therapy followed by aspirin monotherapy after drug-eluting stent implantation: randomized One-Month DAPT trial. American Heart Association Scientific Sessions 2020. 15 November 2020.

106. Bainey KR, Welsh RC, Connolly SJ, et al.; On behalf of the COMPASS Investigators Rivaroxaban plus aspirin versus aspirin alone in patients with prior percutaneous coronary intervention (COMPASS-PCI). Circulation. 2020;141:1141-51.

107. Silvain J, Lattuca B, Beygui F, et al.; ALPHEUS investigators. Ticagrelor versus clopidogre in elective percutaneous coronary intervention (ALPHEUS): a randomised, open-label, phase 3b trial. Lancet. 2020;396:1737-44.

108. Barbato E, Noc M, Baumbach A, et al. Mapping interventional cardiology in Europe: the European Association of Percutaneous Cardiovascular Interventions (EAPCl) Atlas Project. Eur Heart J. 2020;41:2579-88.

109. Timmis A, Townsend N, Gale CP, et al.; European Society of Cardiology. European Society of Cardiology: cardiovascular disease statistics 2019. Eur Heart J. 2020;41:12-85. 